(C) Dereito Vol.28, n²:9-41 (Xullo-Decembro, 2019) • ISSN 1132-9947

\title{
LA PROTECCIÓN PENAL DEL AGUA COMO RECURSO NATURAL. UNA VALORACIÓN CRÍTICA DE LAS DIFERENCIAS ENTRE ESPAÑA Y PORTUGAL
}

The criminal protection of water as a natural resource. A critical assessment of the differences between Spain and Portugal

DOI: http://dx.doi.org/10.15304/dereito.28.2.6193

\author{
VIRXILIO RODRÍGUEZ VÁZQUEZ ${ }^{1}$ \\ Profesor Contratado Doctor de Derecho Penal \\ Universidade de Vigo \\ virxilio@uvigo.es
}

\section{Resumen}

Éste es un estudio de Derecho comparado sobre la protección penal del agua en España y Portugal para reflejar las diferencias entre ambos países, valorar las posibles repercusiones prácticas de aquéllas y hacer propuestas para una homogeneización normativa. Para llevar a cabo este estudio se utiliza el método dogmático, propio de las Ciencias penales, que parte del Derecho positivo contenido en el Código Penal español (CPe) y portugués (CPp) entendido como un «dogma», postulados establecidos por el legislador, para analizarlos siguiendo la teoría del delito, comprobando su coherencia interna y con el propio sistema jurídicopenal. A continuación, se comparan las conductas penalmente relevantes contempladas en uno y otro texto, los resultados exigidos para calificar aquéllas como delitos, así como los sujetos penalmente responsables, y sus penas. Las consideraciones finales tratan de poner de manifiesto las relevantes diferencias existentes entre el CPe y el CPp en materia de protección del agua.

Palabras clave: Medio ambiente; Agua; Mar; Protección penal; Territorialidad.

\footnotetext{
${ }^{1}$ Este trabajo es el resultado de la estancia de investigación desarrollada en la Faculdade de Direito, Universidade Católica de Porto, financiada a través del Programa IACOBUS (Resolución del 24 de octubre de 2018), gestionado por la Agrupación Europea de Cooperación Territorial Galicia-Norte de Portugal (GNP, AECT), con el apoyo de la Unión Europea a través de Programa INTERREG V-A ESPAÑA-PORTUGAL (POCTEP) 2014-2020. El presente trabajo se inscribe en el proyecto de investigación "Responsabilidad penal de personas físicas y jurídicas en el ámbito empresarial, económico, laboral y de los mercados (II)" (Referencia: DER2014-58546-R, Ministerio de Economía y Competitividad), del que es investigador principal el Prof. Dr. Dr. h. c. mult. DiegoManuel Luzón Peña, Catedrático de Derecho Penal de la Universidad de Alcalá de Henares, así como también en el proyecto de investigación "Principios y garantías penales: sectores de riesgo" (Referencia: DER2016-76715-R, Ministerio de Ciencia e Innovación) del que es investigador principal el Prof. Dr. Dres. h. c. Miguel Díaz y García Conlledo, Catedrático de Derecho Penal de la Universidad de León, y de cuyos equipos de trabajo formo parte.
}

Recibido: 28/09/2019. Aceptado: 29/11/2019. 


\section{Abstract}

This is a comparative law study on the criminal protection of water in Spain and Portugal to reflect the differences between the two countries, assess the possible practical repercussions of those and make proposals for a normative homogenization. To carry out this study, the dogmatic method is used, typical of criminal sciences, part of the positive law contained in the Spanish Penal Code (CPe) and Portuguese (CPp) understood as a «dogma», postulates established by the legislator, to analyse them following the theory of crime, checking their internal coherence and with the judicial system itself. Next, the criminally relevant conducts contemplated in both texts are compared, the results required to qualify those as crimes, as well as the criminally liable subjects, and their penalties. The final considerations try to highlight the relevant differences between the CPe and the CPp in terms of water protection.

Keywords: Environment; Water; Sea; Criminal protection; Territoriality.

\section{SUMARIO}

1.- INTRODUCCIÓN.; 2.- LA PROTECCIÓN PENAL DEL AGUA EN ESPAÑA Y EN PORTUGAL.; 2.1.- El agua en el Código Penal español.; 2.2.- El agua en el Código Penal portugués.; 3.- ANÁLISIS CRÍTICO Y COMPARADO DE LA PROTECCIÓN PENAL DEL AGUA COMO RECURSO NATURAL EN ESPAÑA Y PORTUGAL. ; 4.- CONCLUSIONES.; 5.- BIBLIOGRAFÍA.

\section{SUMMARY}

1.- INTRODUCTION.; 2.- THE CRIMINAL PROTECTION OF WATER IN SPAIN AND IN PORTUGAL.; 2.1.- Water in the Spanish Criminal Code. 2.2.- Water in the Portuguese Criminal Code.; 3.- CRITICAL AND COMPARATIVE ANALYSIS OF CRIMINAL WATER PROTECTION AS A NATURAL RESOURCE IN SPAIN AND PORTUGAL.; 4.- CONCLUSIONS.; 5.BIBLIOGRAPHY.

\section{INTRODUCCIÓN ${ }^{2}$}

El art. 45 Constitución Española (CE) considera el derecho a disfrutar del medio ambiente como un derecho subjetivo de todos, con una contrapartida que es la obligación también de todos de conservarlo. Por su parte, el art. 66. ${ }^{\circ}$ Constitución Portuguesa (CPt) todavía se muestra más ambiciosa no sólo al reproducir en su primer apartado la misma idea anterior sino al enumerar las acciones que el Estado debe llevar a cabo para asegurar aquel derecho ${ }^{3}$.

\footnotetext{
2 Las abreviaturas empleadas son las siguientes: art., arts., artículo, artículos; CPe, Código Penal español; CPp, Código Penal Portugués; coord., coordinador(a); dir., director(a); ed., editor(a); km, kilómetro(s); n.o, número; p., página; pp., páginas; s., siguiente; ss., siguientes; VV.AA., varios autores.

3 Un estudio pormenorizado sobre el art. 66.0 CPp puede verse en S.M. DA GRAÇA COITINHO DAS NEVES, A tutela penal do meio ambiente: uma abordagem de sua legitimidade à luz da teoria funcionalista de Claus Roxin, Universidade do Minho, Braga, 2017, pp. 96 ss.
} 
En el Derecho penal contemporáneo, el medio ambiente ha alcanzado el estatus de bien jurídico susceptible de protección. Es discutido, eso sí, cuál es realmente el bien jurídico que inmediatamente se protege en los delitos contra el medio ambiente o contra los recursos naturales ${ }^{4}$. Pero lo

4 Véase ampliamente A. MATEOS RODRÍGUEZ-ARIAS, Derecho penal y protección del
medio ambiente, 1992, Colex, Madrid, pp. $54 \mathrm{sS}$; ; J.M. SILVA SÁNCHEZ, Delitos contra el
medio ambiente, Tirant lo Blanch, Valencia, 1999, pp. 17 SS.; F.J. SOSPEDRA NAVAS,
"De los delitos contra los recursos naturales y el medio ambiente. Capítulo III", en
VV.AA., Delitos relativos a la ordenación del territorio y protección del patrimonio
histórico, medio ambiente y contra la seguridad colectiva (delitos de riesgo catastrófico e
incendios), Bosch, Barcelona, 1999, pp. 171, 183; P.M. DE LA CUESTA AGUADO,
Causalidad de los delitos contra el medio ambiente, 2.a, Tirant lo Blanch, Valencia, 1999,
pp. $18 \mathrm{~s} ., 64$ ss.; N. MATELLANES RODRÍGUEZ, Medio ambiente y funcionarios públicos.
Análisis del tipo objetivo del artículo 329 del Código Penal, Bosch, Barcelona, 2000, pp. 83 ss.; N.J. DE LA MATA BARRANCO, "Derecho comunitario y Derecho estatal en la tutela penal del ambiente", Revista Electrónica de Ciencia Penal y Criminología, 2, 2000, p. 1; N.J. DE LA MATA BARRANCO, "Delitos contra el urbanismo y la ordenación del territorio y delitos contra el ambiente", en VV.AA., Derecho penal económico y de la empresa, Dykinson, Madrid, 2018, pp. 629-684, pp. 662 ss.; P.M. DE LA CUESTA AGUADO, "Energía nuclear: arts. 343 y 345", en VV.AA. (F.J. Álvarez García/J.L. González Cussac, dirs.), Consideraciones a propósito del Proyecto de Ley de 2009 de modificación del Código Penal, Tirant lo Blanch, Valencia, 2010, pp. 353-357, pp. 353 ss. También, C. BLANCO LOZANO, La tutela del agua a través del Derecho penal, Bosch, Barcelona, 2000, pp. 350 ss., quien tras exponer posturas contrarias a la propia sustantividad de las aguas continentales en cuanto bien jurídico protegido y tesis favorables, se muestra alineado con la segunda postura, advirtiendo que «estas características abstracción y amplitud, por tanto, del concepto medio ambiente, aconsejan en aras del principio de seguridad jurídica descomponer -en la medida de lo posible- el mismo, de forma que puedan ser objeto de consideración en el plano jurídico-penal otros bienes más concretos, de más fácil y pacífica aprehensión, cuya consideración jurídica no se vea enturbiada por toda una diversidad y contraposición de planteamientos filosóficos, sociológicos, políticos, económicos, etc. (...) Por lo demás, razones técnicas y prácticas, fundamentalmente de índole concursal, conducen también a la fragmentación del bien jurídico medio ambiente, genéricamente protegido en el Código penal, en otros más concretos objetos de tutela en función de la específica lesividad de la conducta»; brevemente, B.J. FEIJOO SÁNCHEZ, Sanciones para empresas por delitos contra el medio ambiente. Presupuestos dogmáticos y criterios de imputación para la intervención del Derecho Penal contra las empresas, Civitas, Madrid, 2002, pp. 35 s.; en profundidad, M.C. ALASTUEY DOBON, El delito de contaminación ambiental (Artículo 325.1 del Código penal), Comares, Granada, 2004, pp. 15 ss.; A. JORGE BARREIRO, "El bien jurídico protegido en los delitos contra el medio ambiente en el CP de 1995", en VV.AA. (A. Jorge Barreiro, dir./M. Cancio Meliá, coord.), Estudios sobre la protección penal del medio ambiente en el ordenamiento jurídico español, Comares, Granada, 2005, pp. 1-73, passim.; un estudio en profundidad de Política criminal y Dogmática al respecto, L. ESCAJEDO SAN EPIFANIO, El medio ambiente en la crisis del Estado social. Su protección penal simbólica, Comares, Granada, 2006, pp. 68 ss., 304 ss.; J. URRAZA ABAD, Delitos contra los recursos naturales y el medio ambiente, La Ley, Madrid, 2001, pp. 49 ss.; P. RODRÍGUEZ LÓPEZ, Medio ambiente, territorio, urbanismo y Derecho penal, Bosch, Barcelona, 2007, pp. 268 ss.; C.J. CANTERO CERQUELLA, La responsabilidad penal de los funcionarios por delitos ambientales, Reus, Madrid, 2010, pp. 59 ss.; también L. MORILLAS CUEVA, "Las diversas variables de la protección penal del agua en el ámbito punitivo", en VV.AA. (J.M. Peris Riera, dir./P.J. Cuesta Pastor, coord.), La tutela penal del agua, Dykinson, Madrid, 2011, pp. 37-83, pp. 43 ss., quien señala «no es fácil, por un lado, justificar la autonomía del bien jurídico agua, cuando su protección penal está ubicada dentro de títulos generales referidos al medio ambiente, como sucede, por ejemplo, en el Código penal alemán o, en 
que es indudable es que bajo ese paraguas se han tipificado como delitos conductas que tienen como objeto material el agua y que terminan degradando su calidad o poniéndola en peligro. Y esto es así, más allá de cuál sea en esencia el bien jurídico que con estas conductas se pretende proteger. También es así en el Código Penal español (CPe) y en el Código Penal portugués ( $\mathrm{CPp}$ ) como pondré de manifiesto más adelante ${ }^{5}$.

parte, en el español; en ellos la prevalencia del bien jurídico ambiental sobe sus diversas estructuras o partes es innegable, a pesar de la pretendida vaguedad o complejidad del concepto (...). Otra cosa es que como propuesta de lege ferenda, y dada la progresiva intensidad e importancia de la protección del agua, ésta requiera, incluso en los Códigos penales, de una regulación específica, con objeto material y bien jurídico compartido a través del agua en sus muy diferentes facetas no sólo medio ambientales sino también patrimoniales o atentatorias en concreto a la salud. Pero no es esta, como ya ha sido dicho, la situación actual en nuestro Texto punitivo, decantado por la primera de las hipótesis planteadas». Sobre esta cuestión, S. RODRÍGUEZ FERRÁNDEZ, "El agua: bien jurídico-penal protegido", en VV.AA. (J.M. Peris Riera, dir./P.J. Cuesta Pastor, coord.), La tutela penal del agua, Dykinson, Madrid, 2011, pp. 85-120, pp. 105 ss.; C. SUÁREZMIRA RODRÍGUEZ, "El bien jurídico protegido", en VV.AA. (P. Faraldo Cabana, dir./L.M. Puente Aba, coord.), Ordenación del territorio, patrimonio histórico y medio ambiente en el Código Penal y la legislación especial, Tirant lo Blanch, Valencia, 2011, pp. 77-91, pp. 83 ss.; L.M. PUENTE ABA, "Los delitos contra los recursos naturales y el medio ambiente", en VV.AA. (P. Faraldo Cabana, dir./L.M. Puente Aba, coord.), Ordenación del territorio, patrimonio histórico y medio ambiente en el Código Penal y la legislación especial, Tirant lo Blanch, Valencia, 2011, pp. 235-279, pp. 237 s., quien señala tajante que «no existe duda alguna en relación con la identificación del bien jurídico en el art. 325: se trata del 'medio ambiente' (...). Las discrepancias surgen en el momento de otorgar significado a esta expresión»; J.M. SILVA SÁNCHEZ/R. MONTANER FERNÁNDEZ, Los delitos contra el medio ambiente: reforma legal y aplicación judicial, Atelier, Barcelona, 2012, pp. 24 ss.; G. QUINTERO OLIVARES, Derecho penal ambiental, Tirant lo Blanch, Valencia, 2013, pp. 21 ss., 63 ss.; sobre la autonomía del medio ambiente como bien jurídico susceptible de tutela, la discusión se remonta a época romana, véase J.L. ZAMORA MANZANO, "El ilícito penal medio ambiental en Roma: la contaminación y degradación de las aguas en el espacio urbano y rural", en VV.AA. (M. Calzada González/F. Camacho de los Ríos, coords.), El Derecho penal: de Roma al Derecho actual. VII Congreso Internacional y X Iberoamericano de Derecho romano, Edisofer, Madrid, 2005, pp. 675-707, pp. 691 s.; M.D. SERRANO TÁRRAGA/A. SERRANO MAÍLLO/C. VÁZQUEZ GONZÁLEZ, Tutela penal ambiental, 3.a, Dykinson, Madrid, 2017, pp. 146 ss., quienes asumen el concepto de medio ambiente aportado por PERIS RIERA; L. KREMPEL VARELA, "As tutelas constitucional e penal do meio ambiente", Revista de Estudios Politécnicos, 13, 2010, pp. 75-102, pp. 75 ss.; F. TORRÃO/C. ARAGÃO SEIA, Recensión del libro "Vale a pena o Direito penal do ambiente?" de Paulo de Sousa Mendes, Lusíada. Dereito, 13, 2015, pp. 169-171, pp. 169 ss.

${ }^{5}$ Sobre un minucioso estudio de Derecho comparado sobre esta materia entre el español, alemán e italiano, véase C. BLANCO LOZANO, La tutela del agua a través del Derecho penal, Bosch, Barcelona, 2000, pp. 231 a 285. En esta misma obra, el autor realiza una exhaustiva exposición de la protección penal del agua y la política criminal hídrica en otros países, entre los que incluye a Portugal, C. BLANCO LOZANO, La tutela del agua a través del Derecho penal, Bosch, Barcelona, 2000, pp. 600 ss. Un estudio de Derecho comparado entre el alemán y el español puede verse en L. ESCAJEDO SAN EPIFANIO, EI medio ambiente en la crisis del Estado social. Su protección penal simbólica, Comares, Granada, 2006, pp. 217 ss. Sobre un breve estudio de Derecho comparado en esta materia entre el español, alemán e italiano, véase J.M. PERIS RIERA, "La protección penal del agua en España, Alemania e Italia", Diario La Ley, 7366, pp. 1-8, passim.; también L. MORILLAS CUEVA, "Las diversas variables de la protección penal del agua en el ámbito punitivo", en VV.AA. (J. Peris Riera, dir./P.J. Cuesta Pastor, coord.), La tutela 
España y Portugal comparten $658 \mathrm{~km}$ de frontera fluvial, integrados por las cuencas internacionales del Miño/Minho, Limia/Lima, Duero/Douro, Tajo/Tejo y Guadiana6. Entre ambos países se han sucedido las normas convencionales que tenían por objeto (principal o secundario) los recursos hídricos de frontera. Así, el Convenio de 1864 contemplaba por primera vez la temática de los ríos internacionales hispano-lusos. El Anexo I al Tratado de Límites de 1866 completó el régimen de demarcación transfronteriza a través del Reglamento relativo a los ríos limítrofes. Una posterior mejora se hizo con el Canje de Notas de 1906 que aprobaba el Acta General de Demarcación de Frontera, lo que equivalía a demarcar sobre el terreno la línea de frontera de los dos países, así como un Canje de Notas relativo al aprovechamiento industrial de las aguas de los ríos limítrofes de 1912. Un nuevo acuerdo fue el Convenio para regular el aprovechamiento hidroeléctrico del tramo internacional del río Duero de 1927, que fue objeto de una modificación de carácter restrictivo en cuanto a los caudales a derivar a través del Convenio entre España y Portugal para regular el aprovechamiento hidroeléctrico de los tramos internacionales del río Duero y sus afluentes de 1964. Poco tiempo después, en 1968, se firma el Convenio entre España y Portugal para regular el uso y el aprovechamiento hidráulico de los tramos internacionales de los ríos Miño, Limia, Tajo, Guadiana y Chanza, y de sus afluentes.

Todos ellos son antecedentes del Convenio sobre Cooperación para la Protección y el Aprovechamiento Sostenible de las Aguas de las Cuencas Hidrográficas Hispano-portuguesas, que se firmó en la ciudad portuguesa de Albufeira en noviembre de 1998 (Convenio de Albufeira). En vigor desde el 17 de enero de 2000, es hasta la fecha el acuerdo de cooperación en materia medioambiental entre ambos Estados más acabado, con especial atención en la gestión y explotación de las cuencas hidrográficas internacionales.

Buena parte de los recursos hídricos compartidos entre España y Portugal, y que se pueden ver afectados por actividades contaminantes o por intervenciones que modifiquen substancialmente el recurso (nuevas infraestructuras de comunicación, como carreteras, vías ferroviarias, nuevas centrales hidroeléctricas, entre otras), se encuentran en el territorio de la Eurorregión Galicia-Norte de Portugal.

penal del agua, Dykinson, Madrid, 2011, pp. 37-83, pp. 56 ss.; S. RODRÍGUEZ FERRÁNDEZ, "El agua ¿Bien jurídico penal protegido?, en VV.AA. (J. Peris Riera, dir./P.J. Cuesta Pastor, coord.), La tutela penal del agua, Dykinson, Madrid, 2011, pp. 85-120, pp. 109 ss. Sobre un estudio de Derecho comparado en países latinoamericanos, véase R. BARBA ÁLVAREZ, "El agua como derecho fundamental y su protección jurídico-penal", Revista Prolegómenos - Derechos y Valores, 27, 2011, pp. 213-229, <https://doi.org/10.18359/prole.2414>, passim., analizando la criminalización de actos que inciden en el desperdicio del agua.

${ }^{6}$ En profundidad sobre los datos de las cuencas ibéricas, F. VICENTE DÁVILA, Evaluación de impacto ambiental transfronteriza entre España y Portugal, Atelier, Barcelona, 2016, pp. 197 ss. 
La Eurorregión Galicia-Norte de Portugal es una realidad jurídicoadministrativa consolidada desde que en el año 2008 se constituyese la Agrupación Europea de Cooperación territorial Galicia-Norte de Portugal (GNP, AECT), a través del Convenio de Cooperación Territorial Europea (CCTE) firmado entre la Xunta de Galicia y la Comisión de Coordinación y Desarrollo Regional del Norte de Portugal el día 22 de septiembre de 2008, en Santiago de Compostela, al amparo del Reglamento (CE) n. ${ }^{\circ}$ 1082/2006, del Parlamento Europeo y del Consejo, de 5 de julio, sobre Agrupación Europea de Cooperación Territorial (AECT). Se dotaba así de personalidad jurídica a un territorio geográfico transfronterizo integrado por Galicia y la Región Norte de Portugal, con una superficie total de $50.700 \mathrm{~km}$ cuadrados y con 6,35 millones de habitantes ${ }^{7}$.

De cara a poder optar a la financiación enmarcada en el Programa Operativo de Cooperación Transfronteriza España-Portugal (POCTEP), el Plan de Inversiones Conjuntas de la Eurorregión Galicia-Norte de Portugal (2014-2020) (PIC), elaborado por la GNP, AECT, señaló como eje tercero de actuación, el lograr «una Eurorregión puntera en calidad medioambiental y patrimonio». En este sentido, se afirma que entre las señales de identidad de la Región Norte de Portugal y de Galicia están su gran calidad medioambiental, su diversidad ecológica, climática y geográfica, sumado a un importante patrimonio cultural. Expresamente, se advierte que la importancia decisiva del mar, del turismo y del sector primario en el desarrollo económico de la Eurorregión, obligan a mantener niveles de excelencia. Por lo tanto, los esfuerzos del PIC deben ir orientados a la conservación y mejora del patrimonio natural y cultural, a la prevención de los riesgos que amenazan la calidad medioambiental.

En este mismo sentido, la Estrategia de especialización inteligente transfronteriza Galicia-Norte de Portugal (2014-2020) (RIS3Transfronteriza), elaborada por la Axencia Galega de Innovación (GAIN) y por la Comissão de Coordenação e Desenvolvimento Regional do Norte (CCDRN), en el «área estratégica de colaboración en la modernización de las industrias turísticas y creativas», indica que Galicia y la Región Norte comparten una serie de recursos endógenos, como son su patrimonio cultural y natural, incluyendo sus aguas minerales y termales, que son base de este área estratégica para ambas regiones. Alrededor de estos recursos el sector turismo aparece claramente mencionado en ambas estrategias regionales debido a su importancia. La Estrategia Norte 2020 destaca las actividades turísticas y servicios vinculados a la salud, nombradamente el termalismo y la talasoterapia, el fuerte potencial de valorización en las actividades agroalimentarias como el enoturismo, el turismo de naturaleza y el rural, y el náutico (fluvial y marítimo).

Las principales amenazas para la preservación de la calidad del medio ambiente son, precisamente, las que inciden en las calidades del agua y

\footnotetext{
7 Sobre los antecedentes de la GNP, AECT, véase C. CANCELA OUTEDA, "La Eurorregión Galicia-Norte de Portugal: un escenario de cooperación internacional", Razón y Palabra, 74, 2011, pp. 1 ss.; F. VICENTE DÁVILA, Evaluación de impacto ambiental transfronteriza entre España y Portugal, Atelier, Barcelona, 2016, pp. 273 ss.
} 
de los recursos hídricos en su conjunto, tanto interiores como marítimas. Algunos de estos riesgos tienen un origen natural (aunque en su génesis, en algunos casos, se puede identificar la mano del ser humano). Así, el peligro de sequías e inundaciones, vinculado al cambio climático, ante una disminución notable de las precipitaciones, como también la erosión de todo el litoral. Pero otros riesgos tienen un origen humano, incidiendo negativamente de forma directa e inmediata en el agua interior o marítima. Así, en el apartado E.3.P.5. (Valorización y protección del patrimonio natural y cultural) del PIC, se señala expresamente como el $\ll(. .$.$) intenso tráfico de buques con carga potencialmente contaminante -$ el episodio del Prestige está todavía en la memoria colectiva- es un factor de riesgo que es necesario monitorizar». Por su parte, en el apartado E.3.P.7 (Promover la eficiencia de los recursos ambientales), se expone que «la Eurorregión comparte el recorrido de tres de sus cursos fluviales más importantes, el Miño, el Támega y el Limia. Garantizar su saneamiento evitando todo tipo de vertidos contaminantes en ellos (...) son acciones que necesitan actuaciones conjuntas».

Por otra parte, el análisis de Debilidades, Amenazas, Fuerzas y Oportunidades (DAFO) relativo a la calidad medioambiental de la Eurorregión (p. 46 PIC), destaca como debilidades el «nivel de protección baja de la Red Natura 2000», «demasiados niveles de gestión del medio ambiente», «ineficaz protección del patrimonio histórico y natural», «pérdida de la biodiversidad», «procesos de reforestación con especies externas».

Para asegurar la calidad del medio ambiente y de los recursos naturales, especialmente de los recursos hídricos, el PIC establece varias líneas estratégicas que deben marcar las políticas públicas en este contexto: (a) Un plan de coordinación eurorregional de gestión de espacios y riesgos naturales, así como de catástrofes y emergencias que incluya dotación de infraestructuras y equipamiento. (b) Promover proyectos y acciones de gestión integrada de cuencas hidrográficas y de monitorización de la línea costera. (c) Programa integral para un uso sostenible del agua (pp. 68 ss. PIC).

Para hacer frente a las amenazas identificadas en el marco de la Eurorregión para la calidad del agua y, por extensión, del medio ambiente, y evitar que los riesgos procedentes de actividades humanas -industriales, de consumo y transporte- acaben por contaminar el mar y la línea de costa, así como los recursos hídricos del interior, especialmente los ríos y los acuíferos, es necesario promover Políticas públicas de prevención de actividades contaminantes. El Derecho, y en particular el Derecho penal, constituyen un instrumento propio de las sociedades democráticas útil a este fin, pues a través de normas que se aplican coercitivamente, si es preciso, se busca precisamente evitar que se lleven a cabo conductas o acciones que acaben por dañar bienes, intereses o valores esenciales para el desarrollo social.

La protección penal del medioambiente en general, y en concreto, del agua, como recurso natural, plantea retos de suma importancia. Uno de esos retos tiene que ver con el principio de territorialidad de la ley penal 
que en no pocas ocasiones chocará con la casuística que se da en esta clase de delitos, pues, como nos podemos imaginar, el agua no entiende de fronteras $y$, por tanto, tampoco la contaminación a la que se pueda ver sometida. Precisamente por este motivo, la Unión Europea (UE), desde hace tiempo, ha intentado armonizar la normativa en materia de aguas, en general, y en particular en materia de protección, también penal, de este recurso. Una norma de referencia ha sido la Directiva Marco sobre el Agua (2000/60/CE), a la que habría que sumar en materia penal la Directiva 2009/123/CE y la Directiva 2008/99/CE, entre otras.

A pesar de todas las políticas comunitarias, normas convencionales entre ambos Estados y acciones eurorregionales, se mantienen todavía hoy importantes diferencias en la respuesta penal que se contempla en el Derecho positivo de cada Estado miembro en materia medioambiental y lo que aquí particularmente interesa, en relación con el agua como recurso natural necesitado de especial protección.

El presente trabajo tiene como objetivo llevar a cabo un estudio de Derecho comparado sobre la protección penal del agua, tanto interior como marítima, en España y Portugal (con especial incidencia en la Eurorregión Galicia-Norte de Portugal) para (1) reflejar las diferencias normativo-penales, en alguno casos especialmente importantes, que existen entre los dos Estados, (2) valorar las posibles repercusiones prácticas de aquellas y (3) hacer propuestas de homogeneización de la normativa a la luz de las peculiaridades de la Eurorregión Galicia-Norte de Portugal.

Para llevar a cabo este estudio se ha empleado el método dogmático, propio das Ciencias Jurídicas, analizando el Derecho positivo contenido en los Códigos penales aplicables a la Eurorregión, y cada uno de los delitos que pueden tener incidencia en la protección del agua (arts. 325, 326 bis, $327 \mathrm{CPe}$, y art. $279 \mathrm{CPp}$ ). A continuación, se comparan las conductas penalmente relevantes contempladas en uno y en otro texto jurídico, los resultados exigidos para calificar aquellas como delitos, los sujetos que pueden ser penalmente responsables y las penas. En tercer lugar, se hacen propuestas de lege lata, en unos casos, y de lege ferenda, en otros, para permitir una mayor proximidad entre ambos textos normativos.

En definitiva, se intenta poner de manifiesto cómo a pesar de los intentos de coordinación, la legislación penal en materia de recursos hídricos y medio ambiente que se aplica a uno y otro lado de la frontera, presenta diferencias sustanciales, que la hacen en muchas ocasiones ineficaz en su función preventiva, así como en la persecución de conductas contaminantes de ríos, acuíferos y mar.

\section{LA PROTECCIÓN PENAL DEL AGUA EN ESPAÑA Y EN PORTUGAL 2.1. El agua en el Código Penal español}

Son múltiples las referencias que el CPe hace al agua a lo largo de todo el texto ${ }^{8}$. Así, en el art. $247 \mathrm{CPe}$ se contempla un delito de usurpación ${ }^{9}$, en el

\footnotetext{
8 Para una sistematización de estos delitos, véase también, C. BLANCO LOZANO, La tutela del agua a través del Derecho penal, Bosch, Barcelona, 2000, pp. 120, 144 ss.
} 
art. $255 \mathrm{CPe}$ se tipifica un delito de defraudación ${ }^{10}$, en el art. $346 \mathrm{CPe}$ un delito de estragos ${ }^{11}$, en el art. $560 \mathrm{CPe}$ es calificada como un delito contra el orden público la acción de dañar las conducciones o transmisiones de agua interrumpiendo o alterando gravemente el suministro o el servicio ${ }^{12}$,

Este autor señala que «el Derecho penal de las aguas se halla, al igual que todo el Derecho hídrico en general -si bien no en tan gran medida como otros sectores jurídicohidrológicos-, no recogido en un solo cuerpo legal, sino disperso, siendo así hasta la entrada en vigor del nuevo Código penal de 1995, en el que expresamente se prevé la derogación de normas penales especiales de carácter hidrológico». La dispersión a la que se refiere el autor se refleja en las normas contenidas en el CPe 1944/1973, así como en la Ley de 20 de febrero de 1942, por la que se regula el fomento y conservación de la pesca fluvial, la Ley de 31 de diciembre de 1946, sobre represión de la pesca con explosivos o sustancias venenosas y corrosivas, y la Ley de 29 de abril de 1964, sobre energía nuclear, todas ellas derogadas por el CPe 1995; J.M. PERIS RIERA, "La protección penal del agua en España, Alemania e Italia", Diario La Ley, 7366, pp. 1-8, p. 3; el mismo, "Tutela penal del agua", en VV.AA. (J. Peris Riera, dir./P.J. Cuesta Pastor, coord.), La tutela penal del agua, Dykinson, Madrid, 2011, pp. 21-36, pp. 22 s.

${ }^{9}$ Art. $247 \mathrm{CPe}$ : 1 . El que, sin hallarse autorizado, distrajere las aguas de uso público o privativo de su curso, o de su embalse natural o artificial, será castigado con la pena de multa de tres a seis meses. 2. Si la utilidad reportada no excediere de 400 euros, se impondrá la pena de multa de uno a tres meses». En detalle, L. MORILLAS CUEVA, "Las diversas variables de la protección penal del agua en el ámbito punitivo", en VV.AA. (J. Peris Riera, dir./P.J. Cuesta Pastor, coord.), La tutela penal del agua, Dykinson, Madrid, 2011, pp. 37-83, p. 73 ss.; también P.A. RUBIO LARA, "Delitos de distracción del curso de las aguas públicas o privadas sin autorización y de defraudación del agua (artículos 247 y 255 del Código penal)", en VV.AA. (J. Peris Riera, dir./P.J. Cuesta Pastor, coord.), La tutela penal del agua, Dykinson, Madrid, 2011, pp. 191-212, pp. 192 ss.

${ }^{10}$ Art. $255 \mathrm{CPe}$ : «1. Será castigado con la pena de multa de tres a doce meses el que cometiere defraudación utilizando energía eléctrica, gas, agua, telecomunicaciones u otro elemento, energía o fluido ajenos, por alguno de los medios siguientes: $1 .{ }^{\circ}$ Valiéndose de mecanismos instalados para realizar la defraudación. 2.0 Alterando maliciosamente las indicaciones 0 aparatos contadores. 3.0 Empleando cualesquiera otros medios clandestinos. 2. Si la cuantía de lo defraudado no excediere de 400 euros, se impondrá una pena de multa de uno a tres meses». En detalle, L. MORILLAS CUEVA, "Las diversas variables de la protección penal del agua en el ámbito punitivo", en VV.AA. (J. Peris Riera, dir./P.J. Cuesta Pastor, coord.), La tutela penal del agua, Dykinson, Madrid, 2011, pp. 37-83, p. 76 ss.; también P.A. RUBIO LARA, "Delitos de distracción del curso de las aguas públicas o privadas sin autorización y de defraudación del agua (artículos 247 y 255 del Código penal)", en VV.AA. (J. Peris Riera, dir./P.J. Cuesta Pastor, coord.), La tutela penal del agua, Dykinson, Madrid, 2011, pp. 191-212, p. 199 ss.

${ }^{11}$ Véase L. MORILLAS CUEVA, "Las diversas variables de la protección penal del agua en el ámbito punitivo", en VV.AA. (J. Peris Riera, dir./P.J. Cuesta Pastor, coord.), La tutela penal del agua, Dykinson, Madrid, 2011, pp. 37-83, p. 81 s.; en profundidad, D.L. MORILLAS FERNÁNDEZ, "El delito de estragos: especial referencia a los causados por perturbación o interrupción del suministro de agua", en VV.AA. (J. Peris Riera, dir./P.J. Cuesta Pastor, coord.), La tutela penal del agua, Dykinson, Madrid, 2011, p. 317-343, passim.

${ }^{12}$ Art. $560 \mathrm{CPe}:$ «1. Los que causaren daños que interrumpan, obstaculicen o destruyan líneas o instalaciones de telecomunicaciones o la correspondencia postal, serán castigados con la pena de prisión de uno a cinco años. (...) 3. Igual pena se impondrá a los que dañen las conducciones o transmisiones de agua, gas o electricidad para las poblaciones, interrumpiendo o alterando gravemente el suministro o servicio». Véase, L. MORILLAS CUEVA, "Las diversas variables de la protección penal del agua en el ámbito punitivo", en VV.AA. (J. Peris Riera, dir./P.J. Cuesta Pastor, coord.), La tutela penal del agua, Dykinson, Madrid, 2011, pp. 37-83, p. 82 s.; en profundidad, también P.J. CUESTA 
en los arts. $325^{13}, 326^{14}, 326$ bis $^{15}, 327^{16} \mathrm{CPe}$ relativos a delitos contra el medio ambiente, en los delitos relativos a la energía nuclear, arts. $343^{17}$ y

PASTOR, "Delitos relativos al mercado y a los consumidores y delitos contra el orden público", en VV.AA. (J. Peris Riera, dir./P.J. Cuesta Pastor, coord.), La tutela penal del agua, Dykinson, Madrid, 2011, pp. 273-284, pp. 279 ss.

${ }^{13}$ Art. $325 \mathrm{CPe}$ : «1. Será castigado con las penas de prisión de seis meses a dos años, multa de diez a catorce meses e inhabilitación especial para profesión u oficio por tiempo de uno a dos años el que, contraviniendo las leyes u otras disposiciones de carácter general protectoras del medio ambiente, provoque o realice directa o indirectamente emisiones, vertidos, radiaciones, extracciones o excavaciones, aterramientos, ruidos, vibraciones, inyecciones o depósitos, en la atmósfera, el suelo, el subsuelo o las aguas terrestres, subterráneas o marítimas, incluido el alta mar, con incidencia incluso en los espacios transfronterizos, así como las captaciones de aguas que, por sí mismos o conjuntamente con otros, cause o pueda causar daños sustanciales a la calidad del aire, del suelo o de las aguas, o a animales o plantas. 2. Si las anteriores conductas, por sí mismas o conjuntamente con otras, pudieran perjudicar gravemente el equilibrio de los sistemas naturales, se impondrá una pena de prisión de dos a cinco años (...)».

${ }^{14}$ Art. $326 \mathrm{CPe}$ : «1. Serán castigados con las penas previstas en el artículo anterior, en sus respectivos supuestos, quienes, contraviniendo las leyes u otras disposiciones de carácter general, recojan, transporten, valoricen, transformen, eliminen o aprovechen residuos, o no controlen o vigilen adecuadamente tales actividades, de modo que causen o puedan causar daños sustanciales a la calidad del aire, del suelo o de las aguas, o a animales o plantas, muerte o lesiones graves a personas, o puedan perjudicar gravemente el equilibrio de los sistemas naturales. 2. Quien, fuera del supuesto a que se refiere el apartado anterior, traslade una cantidad no desdeñable de residuos, tanto en el caso de uno como en el de varios traslados que aparezcan vinculados, en alguno de los supuestos a que se refiere el Derecho de la Unión Europea relativo a los traslados de residuos, será castigado con una pena de tres meses a un año de prisión, o multa de seis a dieciocho meses e inhabilitación especial para profesión u oficio por tiempo de tres meses a un año».

${ }^{15}$ Art. 326 bis CPe: «Serán castigados con las penas previstas en el artículo 325, en sus respectivos supuestos, quienes, contraviniendo las leyes u otras disposiciones de carácter general, lleven a cabo la explotación de instalaciones en las que se realice una actividad peligrosa $o$ en las que se almacenen o utilicen sustancias o preparados peligrosos de modo que causen o puedan causar daños sustanciales a la calidad del aire, del suelo o de las aguas, a animales o plantas, muerte o lesiones graves a las personas, o puedan perjudicar gravemente el equilibrio de los sistemas naturales».

${ }^{16}$ Art. 327 CPe: «Los hechos a los que se refieren los tres artículos anteriores serán castigados con la pena superior en grado, sin perjuicio de las que puedan corresponder con arreglo a otros preceptos de este Código, cuando en la comisión de cualquiera de los hechos descritos en el artículo anterior concurra alguna de las circunstancias siguientes: a) Que la industria o actividad funcione clandestinamente, sin haber obtenido la preceptiva autorización o aprobación administrativa de sus instalaciones (...)».

17 Art. $343 \mathrm{CPe}$ : «1. El que, mediante el vertido, la emisión o la introducción en el aire, el suelo o las aguas de una cantidad de materiales o de radiaciones ionizantes, o la exposición por cualquier otro medio a dichas radiaciones ponga en peligro la vida, integridad, salud o bienes de una o varias personas, será sancionado con la pena de prisión de seis a doce años e inhabilitación especial para empleo o cargo público, profesión u oficio por tiempo de seis a diez años. La misma pena se impondrá cuando mediante esta conducta se ponga en peligro la calidad del aire, del suelo o de las aguas o a animales o plantas. (...) 3. Cuando de acuerdo con lo establecido en el artículo 31 bis una persona jurídica sea responsable de los delitos recogidos en este artículo, se le impondrá la pena de multa de dos a cinco años. Atendidas las reglas establecidas en el artículo 66 bis, los jueces y tribunales podrán asimismo imponer las penas recogidas en las letras b) a g) del apartado 7 del artículo 33». 
$345^{18} \mathrm{CPe} y$, finalmente, entre los delitos contra la salud pública, el art. $365 \mathrm{CPe}^{19}$.

Todos ellos tienen interés en tanto en cuanto abordan la captación, distribución, uso y reutilización, es decir, el ciclo del agua desde muy diversos puntos de vista. Es más, desde la óptica de la gestión del recurso hay determinados artículos de los enumerados anteriormente que merecerían un estudio monográfico y detallado, pues lo que se pretende proteger en ellos es el patrimonio, el derecho de propiedad del agua o, en su caso, de explotación de este recurso. Sin embargo, en este trabajo me voy a centrar en el tratamiento que el CPe hace del agua como recurso natural, aunque para ello no sólo me refiera a aquellos artículos que se agrupan en el conjunto de los delitos contra los recursos naturales y el medio ambiente, sino que también incluiré en el análisis los arts. 343, 345 y $365 \mathrm{CPe}$. El motivo es que en todos ellos se tipifican conductas que afectan al agua como recurso natural, teniendo además como denominador común el hecho de que con la preservación de la calidad del agua se busca mediatamente proteger la vida y la salud de las personas. El artículo estrella en esta materia es el art. $325 \mathrm{CPe}$, conocido como «delito ecológico», donde se contiene un delito de contaminación en aguas terrestres, subterráneas o marítimas, incluido el alta mar ${ }^{20}$.

18 Art. $345 \mathrm{CPe}$ : «1. El que, contraviniendo las leyes u otras disposiciones de carácter general, adquiera, posea, trafique, facilite, trate, transforme, utilice, almacene, transporte $o$ elimine materiales nucleares $u$ otras sustancias radiactivas peligrosas que causen o puedan causar la muerte o lesiones graves a personas, o daños sustanciales a la calidad del aire, la calidad del suelo o la calidad de las aguas o a animales o plantas, será castigado con la pena de prisión de uno a cinco años, multa de seis a dieciocho meses, e inhabilitación especial para profesión u oficio por tiempo de uno a tres años. 2. El que sin la debida autorización produjere tales materiales o sustancias será castigado con la pena superior en grado. 3. Si los hechos a que se refieren los apartados anteriores se hubieran cometido por imprudencia grave, se impondrá la pena inferior en grado a la señalada en los mismos».

19 Art. $365 \mathrm{CPe}$ : «Será castigado con la pena de prisión de dos a seis años el que envenenare o adulterare con sustancias infecciosas, u otras que puedan ser gravemente nocivas para la salud, las aguas potables o las sustancias alimenticias destinadas al uso público o al consumo de una colectividad de personas». En detalle, L. MORILLAS CUEVA, "Las diversas variables de la protección penal del agua en el ámbito punitivo", en VV.AA. (J. Peris Riera, dir./P.J. Cuesta Pastor, coord.), La tutela penal del agua, Dykinson, Madrid, 2011, pp. 37-83, p. 78 ss.

20 Sobre el «delito ecológico» en el CPe 1944/1973, la aplicación por parte de los tribunales, y la nueva regulación en el CPe 1995, véase J.A. DE VEGA RUIZ, Delitos contra el medio ambiente, ordenación del territorio, patrimonio histórico, flora y fauna en el Código Penal de 1995, Colex, Madrid, 1996, passim. También, L. ESCAJEDO SAN EPIFANIO, El medio ambiente en la crisis del Estado social. Su protección penal simbólica, Comares, Granada, 2006, pp. 41 ss.; sobre antecedentes lejanos de este delito, J.L. ZAMORA MANZANO, "El ilícito penal medio ambiental en Roma: la contaminación y degradación de las aguas en el espacio urbano y rural", en VV.AA. (M. Calzada González/F. Camacho de los Ríos, coords.), El Derecho penal: de Roma al Derecho actual. VII Congreso Internacional y $X$ Iberoamericano de Derecho romano, Edisofer, Madrid, 2005, pp. 675-700, pp. 699 s. También, G. QUINTERO OLIVARES, Derecho penal ambiental, Tirant lo Blanch, Valencia, 2013, p. 153, nos recuerda «que el primer empresario que ingresó en prisión en España, condenado por la Audiencia Provincial de Barcelona por delito ecológico fue por contaminación de las aguas de un río 
En relación con la conducta típica hay que señalar que nos encontramos con un amplísimo elenco de actos que pueden ser constitutivos del delito, pues se habla de realizar emisiones, vertidos, radiaciones, extracciones 0 excavaciones, aterramientos, ruidos, vibraciones, inyecciones 0 depósitos $^{21}$, a las que se añaden «las captaciones de aguas» ${ }^{22}$. Pero además, estos actos podrán ser realizados directa o indirectamente, de modo que se amplía considerablemente el espectro de conductas punibles, admitiéndose la comisión por omisión. Se requiere, eso sí, que la conducta contravenga leyes o disposiciones generales protectoras del medio ambiente, configurándose de este modo como un tipo penal en blanco, haciendo remisión a disposiciones de Derecho administrativo, especialmente prolijas en lo que a la protección de la calidad de las aguas se refiere ${ }^{23}$.

(...)»; N.J. DE LA MATA BARRANCO, "Delitos contra el urbanismo y la ordenación del territorio y delitos contra el ambiente", en VV.AA., Derecho penal económico y de la empresa, Dykinson, Madrid, 2018, pp. 629-684, pp. $661 \mathrm{~s}$.

${ }^{21}$ Véase ampliamente J.M. SILVA SÁNCHEZ, Delitos contra el medio ambiente, Tirant lo Blanch, Valencia, 1999, pp. 35 ss.; C. BLANCO LOZANO, La tutela del agua a través del Derecho penal, Bosch, Barcelona, 2000, pp. 428 ss.; también L. MORILLAS CUEVA, "Las diversas variables de la protección penal del agua en el ámbito punitivo", en VV.AA. (J.M. Peris Riera, dir./P.J. Cuesta Pastor, coord.), La tutela penal del agua, Dykinson, Madrid, 2011, pp. 37-83, pp. 62 ss. Para conocer aspectos prácticos relativos a la pericia para determinar cuándo se puede hablar de contaminación de las aguas véase, A.A. SÁNCHEZ BRAVO, "La protección del dominio público hidráulico", en VV.AA. (A.A. Sánchez Bravo, ed.), Agua: un recurso escaso, 2006, pp. 23-35, passim.; J.M. BERMÚDEZ REQUENA, "Contaminación de acuíferos y prueba pericial de recogida y análisis de muestras de agua: aspectos procesales penales", en VV.AA. (A.A. Sánchez Bravo, ed.), Agua: un recurso escaso, 2006, pp. 45-65, passim.

22 Muy crítico con la redacción de esta conducta típica, J.M. SILVA SÁNCHEZ, Delitos contra el medio ambiente, Tirant lo Blanch, Valencia, 1999, pp. 48 s.; J.M. SILVA SÁNCHEZ/R. MONTANER FERNÁNDEZ, Los delitos contra el medio ambiente: reforma legal y aplicación judicial, Atelier, Barcelona, 2012, pp. 68 ss.; también, J.A. LASCURAÍN SÁNCHEZ, "Elogio del artículo 325 del Código penal", en VV.AA. (A. Jorge Barreiro, dir./M. Cancio Meliá, coord.), Estudios sobre la protección penal del medio ambiente en el ordenamiento jurídico español, Comares, Granada, 2005, pp. 265-294, p. 288.

23 Para una sistematización de esta normativa administrativa, tanto europea, estatal como autonómica, véase A. FORTES MARTÍN, Vertidos y calidad ambiental de las aguas. Regulación jurídico-administrativa, Atelier, Barcelona, 2005, pp. 59 ss.; sobre la relación entre el Derecho penal y el Derecho administrativo en el delito ecológico del art. $325 \mathrm{CP}$, véase A. MATEOS RODRÍGUEZ-ARIAS, Derecho penal y protección del medio ambiente, Colex, Madrid, 1992, pp. 56 ss.; C. TRABADO ÁlVAREZ, Protección penal del Medio ambiente. Derecho penal y normativa extrapenal sobre Medio ambiente, Septem ediciones, Oviedo, 2001, pp. 40 ss.; J.M. PRATS CANUT /M. MARQUĖS I BANQUÉ/C. MORÁN MORA, Derecho penal ambiental y Derecho comunitario. La Directiva IP, Aranzadi, Pamplona, 2002, pp. 81 ss.; L. ESCAJEDO SAN EPIFANIO, El medio ambiente en la crisis del Estado social. Su protección penal simbólica, Comares, Granada, 2006, pp. 118 ss., 130 ss., 176, 200, 230 ss.; J.L. FUENTES OSORIO, "Accesoriedad administrativa y delito ecológico", en VV.AA. (E. Pérez Alonso, coord.), Derecho, globalización, riesgo y medio ambiente, 2012, pp. 707-734, passim.; E.B. MARÍN DE ESPINOSA CEBALLOS, "El principio non bis in ídem: la acumulación de sanciones penales y administrativas en la protección del medio ambiente", en VV.AA. (E. Pérez Alonso, coord.), Derecho, globalización, riesgo y medio ambiente, 2012, pp. 735-758, passim.; W. FRISCH, "Derecho penal y protección del clima. Posibilidades y límites de una 
Por su parte, el objeto material es el agua, tanto terrestre como marítima. El resultado que se exige para entender consumado el delito viene descrito como la conducta que «cause o pueda causar daños sustanciales a la calidad (...) de las aguas». Esto quiere decir que se está castigando del mismo modo la afectación del objeto material y, en su caso, la lesión del bien jurídico, como la mera puesta en peligro, lo cual es susceptible de crítica $^{24}$. Sobre esta cuestión hay que señalar que la polémica está servida desde antes de la entrada en vigor del CPe 1995, ya con el art. 347 bis CPe 1944/1973, predecesor del actual art. 325 CPe. En este sentido, ESCAJENO SAN EPIFANIO indica que, en origen, «la opinión más extendida en la interpretación de este delito, respaldada uniformemente por la jurisprudencia del Tribunal Supremo, entendía que se trataba de un delito de peligro concreto que para su consumación requería un peligro causalmente relacionado con la conducta del sujeto y abarcado por la voluntad y el conocimiento del agente en toda su dimensión. (...) En la actualidad se abre paso la interpretación del art. 325 como delito de idoneidad o de aptitud para causar un daño. El art. $325 \mathrm{CP}$ abre la posibilidad de interpretarlo como dos tipos básicos o uno básico y uno cualificado, y esta posibilidad permite también interpretar cada uno de esos tipos conforme a una diferente estructura típica. Así, pueden combinarse tratamientos como delito de peligro concreto, abstracto o abstracto concreto -una tesis minoritaria ha defendido incluso su tratamiento como delito de lesión o como delito de resultado doble- siendo de todo punto relevante decantarse por una u otra opción a los efectos de establecer con claridad el ámbito de lo punible. Cada vez más autores defienden que estamos ante un delito de peligro abstracto ${ }^{25}$. En la misma

contribución del Derecho penal a la protección del clima conforme a convenios internacionales", Indret, 4, 2015, pp. 7 ss.

24 En este sentido, M. MARQUĖS I BANQUÉ, Artículo 325, en VV.AA. (G. Quintero Olivares, dir./F. Morales Prats, coord.), Comentarios al Código Español, Tomo II, 7.a ed., Aranzadi, Cizur Menor (Navarra), 2016, pp. 807-820, p. 813; N.J. DE LA MATA BARRANCO, "Delitos contra el urbanismo y la ordenación del territorio y delitos contra el ambiente", en VV.AA., Derecho penal económico y de la empresa, Dykinson, Madrid, 2018 , pp. 629-684, p. 680. Una certera valoración sobre la naturaleza de este delito se puede ver en J. TERRADILLOS BASOCO, "Delitos relativos a la protección del patrimonio histórico y del medio ambiente", en VV.AA. (J. Terradillos Basoco, ed.), Derecho penal del medio ambiente, Trotta, Madrid, 1997, pp. 35-59, p. 48.

${ }^{25}$ Véase L. ESCAJEDO SAN EPIFANIO, El medio ambiente en la crisis del Estado social. Su protección penal simbólica, Comares, Granada, 2006, pp. 283 ss., quien a continuación sistematiza la conceptuación que dan los autores defensores de esta última posición. Así, «SILVA SÁNCHEZ entiende que el peligro para el equilibrio de los sistemas naturales hace referencia a un peligro general estadístico, que no precisa constatación en el caso concreto, porque el peligro concreto nos conduciría, a su juicio, a una imputación injusta en los delitos ambientales; PRATS CANUT, por su parte, defiende que estamos ante un delito de doble resultado (uno de lesión y otro de peligro), siguiendo la interpretación que se propone en otros países respecto de los tipos de contaminación de las aguas o del suelo, aunque parte de un concepto formal de bien jurídico en estos delitos. TERRADILLOS entiende que no es necesaria una puesta en peligro concreto de los bienes jurídicos protegidos, aunque sí que la conducta sea idónea para lesionarlos efectivamente, no siendo, por tanto, suficiente con una mera infracción formal. Ya antes, argumentando las ventajas desde el punto de vista de la eficacia de la norma y seguridad 
línea PUENTE ABA señala que «la calificación de este delito en la jurisprudencia es sumamente confusa, y así encontramos resoluciones que lo califican como de peligro concreto, otras de peligro abstracto, y finalmente otras de peligro hipotético ${ }^{26}$, advirtiendo que habiendo sido tradicionalmente mayoritaria la calificación de este delito como de peligro concreto, «con el paso del tiempo se ha venido calificando cada vez más como de peligro hipotético» ${ }^{27}$.

Pero la exigencia de que la acción del sujeto activo incida en alguno de los elementos enumerados por el legislador, entre ellos el agua, ha generado cierta confusión a la hora de delimitar la naturaleza de este delito desde el punto de vista del bien jurídico protegido. Se hace necesario distinguir con claridad entre el bien jurídico y el objeto material del delito. Al respecto, PUENTE ABA señala que «estamos ante un delito de resultado material, es decir, debe constatarse una efectiva alteración del elemento medioambiental afectado por la conducta contaminante. Por consiguiente, será necesario determinar la relación de causalidad entre la conducta concreta ( $v$. gr. El vertido de materiales sólidos o líquidos a las aguas) y el concreto resultado físico producido (v. gr. La modificación sufrida por las aguas receptoras del vertido) ${ }^{28}, 0$, al menos, añadiría yo, su puesta en

jurídica. En la misma línea de un peligro abstracto, pero exigiendo la idoneidad lesiva de la conducta parecen presentar sus propuestas otros autores, como DE LA CUESTA ARZAMENDI O MUÑOZ CONDE, entre otros»; A. MATEOS RODRÍGUEZ-ARIAS, Derecho penal y protección del medio ambiente, Colex, Madrid, 1992, p. 106; G. QUINTERO OLIVARES, Derecho penal ambiental, Tirant lo Blanch, Valencia, 2013, pp. 128 ss.

${ }^{26}$ L.M. PUENTE ABA, Los delitos contra los recursos naturales y el medio ambiente (arts. 325 y 326), en VV.AA. (P. Faraldo Cabana, dir./L.M. Puente Aba, coord.), Ordenación del territorio, patrimonio histórico y medio ambiente, Tirant lo Blanch, Valencia, 2011, pp. 235-279, p. 246.

27 Véase L.M. PUENTE ABA, "Los delitos contra los recursos naturales y el medio ambiente (arts. 325 y 326)", en VV.AA. (P. Faraldo Cabana, dir./L.M. Puente Aba, coord.), Ordenación del territorio, patrimonio histórico y medio ambiente, Tirant lo Blanch, Valencia, 2011, pp. 235-279, pp. 247 ss. Para esta autora, «se configura así un delito de peligro hipotético o delito de aptitud, castigando una acción apta o idónea para producir un peligro para el bien jurídico protegido (el medio ambiente). Aquí el legislador no se limita a describir una acción generalmente peligrosa, pero tampoco llega a exigir la concurrencia de un resultado de peligro concreto para el bien jurídico; habrá que demostrar la peligrosidad de la acción y la posibilidad del resultado de peligro. /...) Habría que acreditar la idoneidad del acto de contaminación para poner en peligro el equilibrio de los sistemas naturales en un determinado contexto fáctico, esto es, hacer una hipótesis sobre si es posible que la conducta y el resultado producidos lleguen a causar una lesión al medio ambiente». En el mismo sentido, M. MARQUĖS I BANQUÉ, "Artículo 325", en VV.AA. (G. Quintero Olivares, dir./F. Morales Prats, coord.), Comentarios al Código Español, Tomo II, 7. a ed., Aranzadi, Cizur Menor (Navarra), 2016, pp. 807-820, p. 813; M.D. SERRANO TÁRRAGA/A. SERRANO MAÍLLO/C. VÁZQUEZ GONZÁLEZ, Tutela penal ambiental, 3.a, Dykinson, Madrid, 2017, pp. 171 ss., toman postura al respecto señalando que «lo cierto es que el tenor literal de la norma no expresa la exigencia de un peligro concreto, y que la estructura del tipo tampoco lo exige, por lo que debemos concluir que nos encontramos ante una figura delictiva de peligro hipotético o potencial, en la que se prohíbe la realización de una serie de conductas aptas o idóneas para la producción de un determinado daño».

${ }^{28}$ L.M. PUENTE ABA, "Los delitos contra los recursos naturales y el medio ambiente (arts. 325 y 326)", en VV.AA. (P. Faraldo Cabana, dir./L.M. Puente Aba, coord.), Ordenación del 
peligro. Sobre esta misma cuestión, explorando el problema central de la relación de causalidad en los delitos medioambientales, DE LA CUESTA AGUADO indica que «nos encontramos entonces, ante delitos que exigen un resultado que consiste en el deterioro de un elemento ambiental protegido directamente por el tipo con cuya destrucción éste (el tipo) se consuma. (...) será preciso constatar, en primer lugar, la existencia del nexo causal entre acción y resultado material (destrucción del elemento medioambiental objeto de la acción). Ello exigirá delimitar las modalidades de acción típicas, pero, sobre todo, el resultado (material) exigido en el tipo. Si se logra demostrar que el resultado es consecuencia de la acción (relación de causalidad) el tipo se habrá consumado. Y posteriormente podrá comprobarse si el resultado afectó al bien jurídico protegido (ya sea medio ambiente ya sea biodiversidad) y en caso contrario excluir la tipicidad de la conducta» ${ }^{29}$. Aplicando esta reflexión a la conducta de «contaminación de las aguas» del art. $325 \mathrm{CPe}$, el mismo autor indica que «atendiendo al concepto de contaminación que se maneja en la Ley 29/1985, de 2 de agosto, de Aguas (hoy derogada conforme al RDL $1 / 2001$, de 20 de julio, por el que se aprueba el texto refundido de la Ley de Aguas), que considera como tal toda acción que altere el agua pudiendo afectar a su función ecológica o a su función económica, se entenderá que 'dañará' el agua quien altere perjudicialmente sus cualidades, con efectos tanto para el uso humano como para su función ecológica. Esta alteración perjudicial puede consistir tanto en la modificación de sus cualidades físicas, químicas o biológicas, como también en la alteración artificial de la temperatura habitual -o normaldel agua» ${ }^{30}$.

territorio, patrimonio histórico y medio ambiente, Tirant lo Blanch, Valencia, 2011, pp. 235-279, p. 239. Antes, P.M. DE LA CUESTA AGUADO, Causalidad de los delitos contra el medio ambiente, 2.a, Tirant lo Blanch, Valencia, 1999, pp. 66 s., «ello quiere decir, sin embargo, que estos objetos medioambientales como pueden ser el suelo, la flora, la fauna, especies animales, etc., pasen a constituirse en bienes jurídicos: son elementos del bien jurídico protegido que se lesiona o menoscaba con su destrucción».

29 P.M. DE LA CUESTA AGUADO, Causalidad de los delitos contra el medio ambiente, 2.a, Tirant lo Blanch, Valencia, 1999, pp. 205 ss.; P.M. DE LA CUESTA AGUADO, "Energía nuclear: arts. 343 y 345", en VV.AA. (F.J. Álvarez García/J.L. González Cussac, dirs.), Consideraciones a propósito del Proyecto de Ley de 2009 de modificación del Código Penal, Tirant lo Blanch, Valencia, 2010, pp. 353-357, pp. 353 ss.

30 Véase, P.M. DE LA CUESTA AGUADO, Causalidad de los delitos contra el medio ambiente, 2.a, Tirant lo Blanch, Valencia, 1999, pp. 210 ss., quien a continuación pone de manifiesto las dificultades de prueba para determinar cuándo se produce esa alteración, teniendo en cuenta los problemas para concretar el estado del agua anterior a la intervención humana objeto de valoración, la concurrencia de efectos acumulados y la dificultad práctica para diferenciarlos. La represión penal de los daños al patrimonio hídrico a través de la acción de contaminar las aguas ya se remonta a época romana como pone de manifiesto J.L. ZAMORA MANZANO, "El ilícito penal medio ambiental en Roma: la contaminación y degradación de las aguas en el espacio urbano y rural", en VV.AA. (M. Calzada González/F. Camacho de los Ríos, coords.), El Derecho penal: de Roma al Derecho actual. VII Congreso Internacional y $X$ Iberoamericano de Derecho romano, Edisofer, Madrid, 2005, pp. 675-700, pp. 690 ss. 
Mención aparte merece la conducta de «captaciones de aguas» en relación con el resultado exigido por el art. $325 \mathrm{CPe}$, en su apartado primero, introducido por Ley Orgánica $1 / 2015$, de 30 de marzo, que desplaza al apartado segundo del mismo artículo, convirtiéndolo en una circunstancia agravante, consistente en que «pudieran perjudicar gravemente el equilibrio de los sistemas naturales». En mi opinión, no es posible realizar el tipo del art. 325.1 CPe a través de la conducta de "captación", pues con ella no se puede causar daños a la calidad de las aguas, sino disminución del caudal. Esta deficiente técnica legislativa genera también problemas en relación con los siguientes apartados del art. $325 \mathrm{CPe}$. Así, si los incisos primero y segundo del apartado segundo se consideran subtipos agravados del apartado primero ${ }^{31}$, interpretación, en mi opinión, lógica, en cuanto tipos derivados exigirán que se verifique la conducta descrita en el tipo básico (captación de aguas), además del resultado material (causar o poder causar daños a la calidad de las aguas) -que, como ya dije, no es posible-, para, verificándose la circunstancia agravante (que puedan perjudicar gravemente el equilibrio de los sistemas naturales), sean de aplicación. Pues bien, como acabo de señalar, eso no es posible. Sólo en el caso de que se considere que dichos incisos contienen tipos autónomos (más graves), entonces sería posible su realización a través de la conducta de captación de aguas, que efectivamente puede perjudicar gravemente el equilibrio de los sistemas naturales.

Las consecuencias jurídicas para estas conductas no son nada desdeñables, pues además de una pena de multa y otra de inhabilitación especial para profesión u oficio, se contempla una pena de prisión de seis meses a dos años. Estas penas se verán agravadas en los casos en que las conductas antes descritas pudieran llegar a perjudicar gravemente el equilibrio de los sistemas naturales, en cuyo caso la prisión sería de dos a cinco años, pudiendo llegar a imponerse en su mitad superior, es decir, entre tres años y seis meses, a cinco años, cuando además se hubiera creado un riesgo de grave perjuicio para la salud de las personas.

$\mathrm{El}$ art. $326 \mathrm{CPe}$ hace referencia a la gestión ilegal de residuos cuando termina afectando o pueda llegar a hacerlo, a la calidad de las aguas. Al igual que en el artículo anterior, el número de conductas que se pueden subsumir en este tipo es grande, necesitándose en todo caso un resultado que, nuevamente aquí, puede ser de lesión o de peligro. Este artículo se remite al anterior a efectos de determinar las consecuencias jurídicas aplicables. En cuanto a la conducta de traslado de residuos contaminantes, la remisión al Derecho de la Unión Europea hay que entenderla hecha al Reglamento (CE) núm. 1013/2006 del Parlamento Europeo y del Consejo, de 14 de junio de 2006, relativo a los traslados de residuos.

Por su parte, en el art. 326 bis CPe se tipifican conductas que tienen que ver con la explotación de instalaciones en las que se realicen actividades

\footnotetext{
31 M. MARQUĖS I BANQUÉ, "Artículo 325", en VV.AA. (G. Quintero Olivares, dir./F. Morales Prats, coord.), Comentarios al Código Español, Tomo II, 7. a ed., Aranzadi, Cizur Menor (Navarra), 2016, pp. 807-820, p. 809.
} 
peligrosas o se almacenen este tipo de sustancias. Se requiere, en la misma línea de los artículos que lo preceden, la causación de daños o al menos la puesta en peligro del agua, siendo las penas las mismas que las establecidas por el art. $325 \mathrm{CPe}$.

Finalmente, el art. $327 \mathrm{CPe}$ establece un subtipo superagravado cuando concurra alguna de las circunstancias en él enumeradas, siendo de interés en este trabajo citar la última de ellas, «que se produzca una extracción ilegal de aguas en período de restricciones». TERRADILLOS BASOCO se muestra muy crítico con esta circunstancia agravante, sólo idónea para incrementar la pena en dos supuestos del tipo básico, captación de aguas o extracción. Así, «en cualquier caso, parece una agravante que difícilmente se explica si no es por consideraciones de coyuntura (el CP de 1995 se aprobó tras una pertinaz sequía), pues en épocas de abundancia de aguas, su extracción o captación no darán lugar ni siquiera al tipo básico por no ser gravemente peligrosas para el medio ambiente. $Y$ en período de sequía, la escasez de agua normalmente será condicionante de la gravedad del tipo básico. Parece, pues, que al igual que ocurre con los apartados b), c) y d), el legislador ha querido utilizar la agravante para reforzar los mecanismos de control del consumo de agua en los períodos de restricciones, llevando al $\mathrm{CP}$ lo que no debe ser sino una infracción de la Ley de Aguas y de su Reglamento, con la inevitable consecuencia de obligar al intérprete del artículo 326 a una lectura restrictiva del mismo y a la exigencia de establecer un nexo entre la ilegalidad de la extracción y el incremento del peligro propio del tipo básico» ${ }^{32}$. En la misma línea, SILVA SÁNCHEZ para quien «en realidad, casi todos los elementos de este tipo cualificado se dan ya en el correspondiente tipo básico (captaciones de aguas, infracción de normas administrativas, peligro grave para el medio ambiente). El elemento peculiar viene dado, por un lado, por el factor temporal de que ello suceda en un período de restricciones; $y$, por el otro, por la exigencia de ilegalidad y no de la mera infracción de otras disposiciones de carácter general. (...) hay que dilucidar si se contiene ahí [scil. en la expresión "en período de restricciones"] una referencia material a la existencia de sequía o es preciso que el estado de restricción y su duración previsible se declaren a través de la norma correspondiente. La duda afecta, por tanto, en particular, a la cuestión técnica de si nos hallamos ante una ley temporal en sentido material o en sentido formal. $Y$ tiene la obvia repercusión de qué ocurre cuando tales extracciones tienen lugar en períodos de gran sequía no calificados normativamente como de 'restricciones'. Por razones de seguridad jurídica parece que, de entrada, debe exigirse la existencia de una disposición formal que establezca las

32 J. TERRADILLOS BASOCO, "Delitos relativos a la protección del patrimonio histórico y del medio ambiente", en VV.AA. (J. Terradillos Basoco, ed.), Derecho penal del medio ambiente, Trotta, Madrid, 1997, pp. 35-59, p. 48. p. 52. Este autor se refiere al subtipo agravado contenido en el art. 326 de la versión original del CP 1995. Actualmente, tras la reforma del CP operada por LO 1/2015, de 30 de marzo, dicho contenido (sin alteración alguna), se recoge en el art. 327 CP. 
restricciones» ${ }^{33}$. Más recientemente, DE LA MATA BARRANCO señala que «la sexta circunstancia (letra f) -extracción ilegal de agua en período de restricciones-, cuya aplicación sólo tiene sentido en relación a la actividad del artículo 325.1 de 'captaciones de aguas', es la que menos explicación tiene; la que puede encontrarse ha de asociarse a la época en que se tramitó el Código de 1995, de grave sequía. Lo que no puede olvidarse, a pesar de que el texto invite a ello, es que estamos ante un tipo agravado y la mera ilegalidad no basta si la captación no ha implicado, al menos, el daño aunque sea potencial para la calidad de los elementos o recursos naturales que requiere el art. $325.1 \gg^{34}$.

Cabe hacer mención especial al sujeto activo de los delitos expuestos más arriba. Se trata de delitos comunes, que pueden ser cometidos por cualquiera, pero que desde la reforma operada en el CPe mediante LO $5 / 2010$, de 22 de junio, también pueden dar lugar a responsabilidad penal de personas jurídicas conforme a lo dispuesto en el art. $328 \mathrm{CPe}$, en relación con el art. 31 bis $\mathrm{CPe}^{35}$. Todos estos artículos, en su redacción actual, son el resultado de la reforma del CPe llevada a cabo a través de la LO 1/2015, de 30 de marzo, que modificó sustancialmente los delitos ambientales para adaptarlos a la Directiva 2009/123/CE y a la Directiva 2008/99/CE.

33 J.M. SILVA SÁNCHEZ, Delitos contra el medio ambiente, Tirant lo Blanch, Valencia, 1999, pp. 122 s.; véase también L.M. PUENTE ABA, "Los delitos contra los recursos naturales y el medio ambiente (arts. 325 y 326)", en VV.AA. (P. Faraldo Cabana, dir./L.M. Puente Aba, coord.), Ordenación del territorio, patrimonio histórico y medio ambiente, Tirant lo Blanch, Valencia, 2011, pp. 235-279, pp. 278 s.

${ }^{34}$ N.J. DE LA MATA BARRANCO, "Delitos contra el urbanismo y la ordenación del territorio y delitos contra el ambiente", en VV.AA., Derecho penal económico y de la empresa, Dykinson, Madrid, 2018, pp. 629-684, p. 678.

${ }^{35}$ Valorando esta modificación del CP en lo que al Derecho ambiental se refiere, y más en concreto a los recursos hídricos, véase L. MORILLAS CUEVA, "Las diversas variables de la protección penal del agua en el ámbito punitivo", en VV.AA. (J.M. Peris Riera, dir./P.J. Cuesta Pastor, coord.), La tutela penal del agua, Dykinson, Madrid, 2011, pp. 37-83, p. 70; en detalle, L.M. PUENTE ABA, "Los delitos contra los recursos naturales y el medio ambiente (arts. 325 y 326)", en VV.AA. (P. Faraldo Cabana, dir./L.M. Puente Aba, coord.), Ordenación del territorio, patrimonio histórico y medio ambiente, Tirant lo Blanch, Valencia, 2011, pp. 235-279, pp. 256 ss., con una análisis específico de los supuestos de concurrencia de diferentes empresas en la realización del hecho delictivo, con especial referencia a los casos de autoría accesoria. Un análisis minucioso sobre la problemática de la responsabilidad penal de las personas jurídicas en relación con delitos ambientales y, en particular, sobre las cuestiones relativas a la transnacionalidad, véase G. QUINTERO OLIVARES, Derecho penal ambiental, Tirant lo Blanch, Valencia, 2013, pp. 89 ss. Sobre las consecuencias jurídicopenales a personas jurídicas por la realización del delito medioambiental en la esfera, contexto social o seno de la persona colectiva, antes de la reforma de 2010 del CPe, véase ampliamente, J. FEIJOO SÁNCHEZ, Sanciones para empresas por delitos contra el medio ambiente. Presupuestos dogmáticos y criterios de imputación para la intervención del Derecho Penal contra las empresas, Civitas, Madrid, 2002, passim.; N.J. DE LA MATA BARRANCO, "Delitos contra el urbanismo y la ordenación del territorio y delitos contra el ambiente", en VV.AA., Derecho penal económico y de la empresa, Dykinson, Madrid, 2018, pp. 629-684, p. 681. Un análisis específico de la peculiar figura del ecoauditor se puede ver en R. MONTANER FERNÁNDEZ, "La posible responsabilidad penal del auditor ambiental", Indret, 2, 2012, pp. 1-27, passim. 
Por último, aunque no menos importante, se debe advertir que el $\mathrm{CPe}$, mediante su art. 331, tipifica también la modalidad imprudente, de manera que no sólo se castiga la conducta realizada con la intención de contaminar, lo cual en muchas ocasiones se llevará a cabo con dolo eventual, sino también cuando sea realizada por negligencia, por falta de cuidado, o incurriendo en un error de tipo, lo cual no será poco frecuente. En estos casos, la pena se rebajará en un grado respecto a la establecida en la modalidad dolosa, pero seguirá siendo una pena importante, pues en los subtipos agravados partiremos de un marco penal que podrá alcanzar los dos años de prisión.

Aun formando parte de otro título del CPe, en concreto del Título XVII, desarrollado bajo la rúbrica «De los delitos contra la seguridad colectiva», lo cierto es que el art. $343 \mathrm{CPe}$ supone una continuación del art. $325 \mathrm{CPe}$, hasta el punto de que podría ser considerado una suerte de subtipo agravado de éste. En efecto, aquel artículo contiene un delito de contaminación mediante el vertido, la emisión o la introducción en las aguas de materiales radiactivos o radiaciones ionizantes. La estructura del delito es la misma, pues nuevamente se requiere un resultado de peligro para la calidad de las aguas, no siendo necesaria la afectación efectiva de ésta. La diferencia está en el medio empleado, pues en este caso se requiere utilizar elementos radiactivos en la realización de la conducta, y la mayor potencialidad lesiva de éstos es lo que motiva el incremento de las penas al fijar el legislador una pena de prisión de seis a doce años. Así, cuando nos encontremos ante este tipo de conductas, es decir, una acción contaminante que ponga en peligro la calidad de las aguas empleando para ello materiales radiactivos, los hechos deberán ser subsumidos en el art. $343 \mathrm{CPe}$ (aplicando el principio de especialidad, art. 8.1. a CPe). Una vez más, tras la reforma operada por LO 5/2010, de 22 de junio, se contempla la posibilidad de que se exija por estos hechos responsabilidad penal a las personas jurídicas. $Y$ también para este delito se tipifica la modalidad imprudente en el art. $344 \mathrm{CPe}$.

$\mathrm{El}$ art. $345 \mathrm{CPe}$ califica como delito las conductas de posesión, tráfico, facilitación, trato, transformación, utilización, almacenamiento, transporte y eliminación de materiales nucleares u otras sustancias radiactivas, con capacidad para causar daños en la calidad de las aguas. La enumeración de tantas conductas y tan diferentes hace que puedan quedar abarcadas muchas acciones, pero también que se equiparen conductas que, en sí mismas, parecieran que presentan una distinta capacidad de crear un peligro para la calidad de las aguas, aunque sólo sea por el hecho de la distancia que algunas de ellas puedan guardar con el objeto material sobre el que se exige que recaigan. En todo caso, lo que se requiere es, una vez más, que tengan la capacidad de poner en peligro dicha calidad de las aguas. Se debe señalar que, en la práctica, las conductas que tendrán encaje en este precepto son las que consistan en procesar o reciclar materiales radiactivos, o en llevar a cabo depósitos en cementerios nucleares, y así se debe entender el verbo típico «eliminar», pues como bien es sabido, hoy por hoy no se puede hacer desaparecer este tipo de materiales. Otra vez, una pena de prisión de uno a cinco 
años, que se rebajará en un grado si los hechos son cometidos por imprudencia. Pero a diferencia de los anteriores casos, no está prevista la responsabilidad penal de las personas jurídicas, al no haberse introducido por la reforma de LO 5/2010, de 22 de junio, pero tampoco por la de 2015, de transposición de la Directiva 2008/99/CE.

Por último, creo conveniente hacer mención del art. $365 \mathrm{CPe}$, ubicado entre los delitos contra la salud pública. A diferencia de los anteriores, con este delito no se persigue la protección del agua como recurso medioambiental, tenga o no como finalidad última la protección de la vida y salud de las personas, como ocurre en los artículos precedentes; sino la protección inmediata de la vida y salud de las personas. La conducta consiste en envenenar o adulterar con sustancias infecciosas las aguas potables destinadas al uso público o al consumo de una actividad de las personas. No se trata, simplemente, de la afectación a la calidad de las aguas, ni tan siquiera que se produzca una reducción de su aptitud para el consumo o uso humano, sino que se requiere la creación de un grave peligro, por tanto, la incorporación al agua de sustancias muy tóxicas y gravemente nocivas para las personas, y en cantidades que tengan la potencialidad, al menos, de alcanzar a un conjunto de personas. Hay que apuntar, que «el agua típicamente relevante a los efectos de este delito, lo será aquella destinada a consumo de boca, o a entrar en contacto con los alimentos -destinada a cocinar, lavar alimentos, etc.-, e incluso podrían admitirse usos no estrictamente vinculados con la alimentación, como por ejemplo la higiene y el aseo personal». La pena de prisión que se establece para este delito es de dos a seis años, contemplándose la posibilidad de que se responsabilice a las personas jurídicas (art. 366 $\mathrm{CPe}$ ), así como la modalidad imprudente (art. $367 \mathrm{CPe}$ ).

\subsection{El agua en el Código Penal portugués}

El CPp también recoge varios artículos con referencia al agua, sin bien en menor número que los contemplados en el CPe. Así, el art. $2040^{36} \mathrm{CPp}$, donde se tipifica el hurto cualificado, el art. $215^{37} \mathrm{CPp}$, referido a la usurpación, el art. $277^{38} \mathrm{CPp}$, que contempla el delito de daños en

\footnotetext{
${ }^{36}$ Art. 204.0 CPp: «1 - Quien hurte una cosa mueble ajena: (...); j) Impidiendo o perturbando, por cualquier medio, la explotación de servicios de comunicaciones o la prestación de servicio público de agua, luz, energía, calor, aceite, gasolina o gas. (...)».

37 Art. $215 .^{\circ} \mathrm{CPp}$ : «1 - Quien, por medio de violencia o amenaza grave, invadir o ocupar cosa inmueble ajena, con intención de ejercer el derecho de propiedad, posesión, uso o servidumbre no tutelados por ley, sentencia o acto administrativo, es castigado con pena de prisión hasta 2 años o con pena de multa hasta 240 días, si no correspondiese pena más grave en atención al medio empleado. 2 - La pena prevista en el número anterior es aplicable, por los medios indicados en el número anterior, a desviar o represar aguas, sin que se tenga el derecho a eso, para sí mismo o para otra persona, obteniendo beneficio ilegítimo».

38 Art. 277.0 CPp: «1 - Quien: (...) c) Destruya, dañe o inutilice, total o parcialmente, instalación para aprovechamiento, producción, almacenamiento, conducción o distribución de agua, aceite, gasolina, calor, electricidad, gas o energía nuclear, o para protección contra fuerzas de la naturaleza; o d) Impida o perturbe la explotación de servicios de comunicaciones o el suministro al público de agua, luz, energía o calor,
} 
instalaciones. Un delito contra la seguridad en el transporte y comunicaciones, cuando se hacen a través del agua, es el que se establece en los arts. $288^{039}$ y $289^{040}$ CPp. Finalmente, en el art. $2790^{41}$ $\mathrm{CPp}$, se tipifica un delito de contaminación ambiental.

A efectos del presente trabajo y mejor rendimiento en la tarea de comparación entre ambos códigos penales, el único artículo del CPp que

substrayendo o desviando, destruyendo, dañando o inutilizando, total o parcialmente, cosa o energía que sirve tales servicios; y cree de este modo peligro para la vida o para la integridad física de otro, o para bienes patrimoniales ajenos de valor elevado, será castigado con pena de prisión de 1 a 8 años. 2 - Si el peligro referido en el número anterior fuese creado por negligencia, el agente será castigado con pena de prisión de hasta 5 años. 3 - Si la conducta referida en el n. ${ }^{\circ} 1$ fuese realizada por negligencia, el sujeto será castigado con pena de prisión de hasta 3 años o con pena de multa».

39 Art. 288. ${ }^{\circ} \mathrm{CPp}:$ : 1 - Quien atente contra la seguridad del transporte por aire, agua o ferrocarril $(\ldots) \gg$.

${ }^{40}$ Art. 289.0 CPp: «1 - Quien conduzca vehículo destinado al transporte por aire, agua o ferrocarril, no estando en condiciones de hacerlo con seguridad o violando gravemente las reglas de conducción (...)».

${ }^{41}$ Art. 279.0 CPp: «1 - Quien, no observando disposiciones legales, reglamentarias u obligaciones impuestas por la autoridad competente en conformidad con aquellas disposiciones, provoque contaminación sonora o contamine el aire, el agua, el suelo, o de cualquier forma degrade las calidades de estos componentes ambientales, causando daños substanciales, será castigado con la pena de prisión de hasta 5 años. 2 - Quien, no observando disposiciones legales, reglamentarias u obligaciones impuestas por la autoridad competente en conformidad con aquellas disposiciones, cause daños substanciales a la calidad del aire, del agua, del suelo, o a la fauna o a la flora, al proceder: a) a la descarga, a la emisión o a la introducción de materias ionizantes o de radiaciones ionizantes en la atmósfera, en el suelo o en el agua; b) a las operaciones de recogida, transporte, almacenaje, clasificación, tratamiento, valorización y eliminación de residuos, incluyendo el tratamiento posterior de los locales de eliminación, así como las actividades ejercidas por negociantes e intermediarios; c) a la explotación de instalaciones donde se ejerza actividad peligrosa o donde sean almacenadas o utilizadas substancias o mezclas peligrosas; o d) a la producción, al tratamiento, a la manipulación, a la utilización, a la detención, al almacenamiento, al transporte, a la importación, a la exportación o a la eliminación de materiales nucleares o de otras substancias radioactivas peligrosas; será castigado con la pena de prisión de hasta 5 años. 3- Cuando las conductas descritas en los números anteriores fuesen susceptibles de causar daños substanciales a la calidad del aire, del agua o del suelo o a la fauna o a la flora, el agente será castigado con la pena de prisión de hasta 3 años o con pena de multa de hasta 600 días. 4 - Si las conductas referidas en los números 1 y 2 fuesen realizadas por negligencia, el agente será castigado con pena de prisión de hasta 2 años o con pena de multa de hasta 360 días. 5 - Si las conductas referidas en el n. 03 fuesen practicadas por negligencia, el agente será castigado con pena de prisión de hasta 1 año o con pena de multa de hasta 240 días. 6 - Para los efectos de los números 1,2 y 3, son daños substanciales aquellos que: a) perjudiquen, de modo significativo o duradero, la integridad física, así como el bien-estar de las personas en relación con la naturaleza; b) Impidan, de modo significativo o duradero, la utilización de un componente ambiental; c) Diseminen microrganismo o substancia perjudicial para el cuerpo o la salud de las personas; d) Causen un impacto significativo sobre la conservación de las especies o de sus hábitats; o e) Perjudiquen, de modo significativo, la cualidad o el estado de un componente ambiental. 7 - Cuando fuesen efectuadas descargas de substancias contaminantes por navíos, de forma aislada o reiterada, de las cuales resulte deterioro de la cualidad del agua, el agente será punido con pena de prisión de hasta 5 años. 8 - Si la conducta referida en el número anterior fuese practicada por negligencia, el agente será castigado con pena de prisión de hasta 2 años o con pena de multa de hasta 360 días». 
presenta interés es el último mencionado ${ }^{42}$. Consecuentemente, el análisis se reduce de forma necesaria y significativa respecto al $\mathrm{CPe}$, como también la literatura científica existente en la materia, algo que enseguida se podrá comprobar.

El art. 2790 CPp tipifica un delito de contaminación, abarcando también la que tiene incidencia en el agua. De hecho, la propia rúbrica del artículo es explícita, pues habla de Poluição (polución), siendo la conducta típica contaminar el agua o por cualquier forma degradar la calidad de este componente ambiental, causando daños substanciales. Este último inciso es el resultado exigido, lo cual significa que se debe producir un resultado lesivo para que se pueda imponer una pena de prisión que puede llegar a alcanzar los cinco años. Esta misma pena de prisión se impondrá, según el apartado dos del mismo artículo, a quien sin dirigir su conducta directamente a contaminar lleve a cabo acciones que terminen provocando el mismo resultado, cuando se trate de descargar, emitir o introducir materiales ionizantes o radiaciones ionizantes en el agua, así como la producción, tratamiento, manipulación, eliminación de materiales nucleares $u$ otras substancias radioactivas peligrosas, y conductas de transporte, almacenamiento, clasificación, entre otras muchas, de cualquier otra substancia o material peligroso. De este delito se diferencia el tipificado en el apartado tres del mismo artículo, pues se recoge aquí un delito de peligro cuando las conductas descritas anteriormente fueran susceptibles de causar daños substanciales a la calidad del agua, atribuyéndole una pena de hasta tres años de prisión.

Merece especial mención el apartado siete donde se recoge como delito la contaminación marítima provocada por buques, de forma puntual o recurrente. Se está pensando fundamentalmente en las conductas de limpieza de los tanques de combustible que tan frecuentemente suceden, muchas veces próximos a las costas. La pena es de cinco años de prisión. Las penas señaladas se rebajan considerablemente en caso de que los hechos se realizasen por imprudencia, pasando a una pena de prisión de hasta dos años, de hasta un año y de hasta dos años respectivamente ${ }^{43}$.

El propio artículo nos da una interpretación auténtica de lo que se entiende por «daños substanciales», lo cual es importante pues se trata

\footnotetext{
${ }^{42}$ Introducido en el CPp a través del Decreto-Ley n.0 48/1995, de 15 de marzo. Para un estudio en profundidad sobre la redacción originaria del tipo penal, véase A.M. RODRIGUES, "A propósito do crime de poluição (artigo 279.0 do Código Penal)", Direito e Justiça. Revista da Faculdade de Direito da Universidade Católica Portuguesa, 12, 1998, pp. 126 ss. Sobre las sucesivas reformas de este artículo en el CPp y sus diversas interpretaciones, véase M.P. RIBEIRO FARIA, "Direito penal do ambiente - sua reforma e perspectivas de evolução", Revista do CEJ, 2, 2008, pp. 27 ss.; S.M. DA GRAÇA COITINHO DAS NEVES, A tutela penal do meio ambiente: uma abordagem de sua legitimidade à luz da teoria funcionalista de Claus Roxin, Universidade do Minho, Braga, 2017, pp. 452 ss.

${ }^{43}$ Véase, J. DE FIGUEIREDO DIAS, Comentário Conimbricense do Código Penal, Tomo II, Coimbra Editora, Coimbra, 1999, pp. 1000 ss.; muy críticos con este artículo y, en general, con la tipificación de los delitos contra el medio ambiente en el CPp se muestran F. TORRÃO, C. ARAGÃO SEIA, Recensión del libro "Vale a pena o Direito penal do ambiente?" de Paulo de Sousa Mendes, Lusíada. Dereito, 13, 2015, pp. 169-171, p. 170.
} 
de un elemento típico capital a la hora de valorar una conducta y poder subsumirla en este artículo. La sustancialidad del daño tiene que ver, fundamentalmente, con el carácter permanente del mismo, o bien en la integridad física o bienestar de las personas, o bien afectando a la utilización de un componente ambiental, en el caso que nos atañe, del agua $^{44}$. Por su parte, el art. 2790-A CPp tipifica un delito de traslado de residuos con capacidad para causar daños en el medioambiente, siempre que se trate de una actividad abarcada por el ámbito de aplicación del art. 2.35 Reglamento (CE) n.o 1013/2006, de 14 de junio.

\section{ANÁLISIS CRÍTICO Y COMPARADO DE LA PROTECCIÓN PENAL DEL AGUA COMO RECURSO NATURAL EN ESPAÑA Y PORTUGAL}

De la exposición de los delitos contra el medio ambiente, en sentido amplio, tipificados en el CPe y en el CPp, con especial referencia al agua, y desde un punto de vista de Derecho comparado, se pueden extraer las siguientes valoraciones.

Cabe decir que entre ambos Códigos Penales existe un paralelismo en la tipificación de conductas que atentan contra el medio ambiente y que tienen el agua como elemento de referencia. En este sentido, el art. 325 $\mathrm{CPe}$ y el art. $279 \mathrm{CPp}$ son, estructuralmente, uno reflejo del otro. Sin embargo, a partir de ahí las diferencias son sensibles $y$, en algunos casos, muy relevantes.

En primer lugar, el objeto material se describe con distinta precisión pues mientras que el $\mathrm{CPe}$ se refiere a las «aguas terrestres, subterráneas o marítimas, incluido la alta mar», el CPp se limita a hablar lacónicamente de la contaminación del «agua». En cuanto a la técnica legislativa elegida hay que advertir que mientras el legislador portugués diferencia claramente entre delitos de peligro y lesión en materia medioambiental,

\footnotetext{
44 Véase, L. KREMPEL VARELA, "As tutelas constitucional e penal do meio ambiente", Revista de Estudios Politécnicos, 13, 2010, pp. 75-102, pp. 90 ss.; J. SOUTO DE MOURA, "Crimes Ambientais. Jornada sobre a revisão do Código Penal", Revista do CEJ, 8,2008 , p. 361 , constata que «en materia de Política criminal ha habido, en la temática de los delitos contra el medio ambiente, y especialmente, en el de contaminación, una ampliación de la aplicación del sistema penal en este sector, bien sea por la gravedad de las penas aplicables, bien sea por el número de conductas que han sido elevadas a la categoría de delito»; por su parte, S.M. DA GRAÇA COITINHO DAS NEVES, A tutela penal do meio ambiente: uma abordagem de sua legitimidade à luz da teoria funcionalista de Claus Roxin, Universidade do Minho, Braga, 2017, pp. 460 ss., valora muy positivamente las sucesivas reformas del CPp en esta materia, señalando que «en lo que se refiere a la contaminación, se ha de destacar la importancia y legitimidad de la ampliación de la protección penal, que se considera como acertada, teniendo en cuenta el gran impacto de la actividad humana sobre el planeta. (...) En esa línea se ha de concluir que el legislador portugués hizo bien cuando optó por el incremento de las penas aplicadas a las conductas ya existentes, por el elevar el número de conductas que quedan abarcadas por el tipo y también por la utilización del Derecho administrativo en sus aspectos general y especial (accesoriedad de derecho y de acto) en las situaciones de 'daños substanciales', perfeccionando, por tanto, la protección penal respecto a la preexistente. Con esto, el antropocentrismo va poco a poco abandonando el escenario delictivo penal ambiental portugués, dando lugar a la protección del bien jurídico medio ambiente en la forma supraindividual de la conducta contaminante».
} 
asignando penas fácilmente diferenciables en uno y otro caso, el legislador español no es taxativo y preciso, confundiendo, o al menos generando la confusión, entre delitos de lesión y de peligro, hasta el punto de asignar por lo menos, aparentemente- la misma consecuencia jurídica en uno y en otro caso. Así lo pone de manifiesto la expresión «cause o pueda causar daños sustanciales a la calidad (...) de las aguas (...)».

En segundo lugar, en relación con el resultado exigido, sea éste de peligro - de lesión, mientras el legislador portugués proporciona una interpretación auténtica de lo que hay que entender por «daños substanciales», el legislador español no lo hace, de modo que dificulta considerablemente la interpretación del tipo, pues nos encontramos ante un concepto jurídico indeterminado que, a la postre, genera inseguridad jurídica e indefensión. Es cierto, eso sí, que siendo loable el intento del legislador portugués por proporcionar una interpretación auténtica, que algo ayuda, se queda lejos de lograr el objetivo de cerrar el significado de dicha expresión y generar así un marco de juego acotado a los operadores jurídicos. Y ello porque para definir «daños substanciales» acude a expresiones tan vagas como los que «perjudiquen, de modo significativo y duradero, la integridad física», «impidan, de modo significativo y duradero, la utilización de un componente ambiental», «causen un impacto significativo sobre la conservación de las especies o de los hábitats», o «perjudiquen, de modo significativo, la calidad o el estado de un componente ambiental».

En tercer lugar, el legislador portugués incluye un tipo específico para los casos de contaminación producida por barcos como consecuencia de descargas de sustancias contaminantes que terminan por afectar a la calidad del agua, cosa que no se recoge así en el CPe. En mi opinión, sería deseable un tipo de estas características en un Estado que se aproxima a los $6.000 \mathrm{~km}$ de costa, por tanto, también con un extenso mar territorial, sin que ello signifique que aquellas conductas no puedan ser subsumidas en los tipos penales existentes actualmente en el CPe.

En cuarto lugar, es llamativa la diferencia que existe en las consecuencias jurídicas que se atribuyen a estos delitos en uno y otro código. En los tipos básicos, las penas previstas en general en el $\mathrm{CPe}$, al menos en relación con la pena de prisión, son en su marco abstracto inferiores a las contempladas en el CPp, pues frente a los dos años de prisión nos podemos encontrar con hasta cinco años de prisión. Sin embargo, en los subtipos agravados se dan diferencias en sentido contrario. Es más, en los delitos relativos a materiales radiactivos, las penas pueden llegar hasta los doce años de prisión en el CPe.

En quinto lugar, una de las cuestiones que deben ser analizadas cuando hablamos de acciones contaminantes sobre el agua es la relativa a la territorialidad. No es posible aquí un análisis detallado de esta cuestión, pues excedería con mucho las pretensiones de este trabajo, pero sí creo necesario realizar algunas observaciones al respecto.

Desde luego, en los delitos medioambientales y, en concreto, en los que se realizan sobre el agua, es pertinente el debate sobre la Ley penal en el espacio (desde un punto de vista de Derecho penal substantivo y 
procesal), así como del lugar de comisión del delito. Las acciones, por ejemplo, de vertidos de productos tóxicos en un río, con alta probabilidad acabarán cruzando fronteras y generar el daño efectivo o la posibilidad de ese daño fuera del territorio español. Esta hipótesis es factible precisamente en cuencas hidrográficas compartidas entre España y Portugal, como son las del río Miño, Duero, Tajo y Guadiana ${ }^{45}$. Lo mismo se puede decir en relación con acciones de vertidos al mar, siendo la costa española y portuguesa un continuo tanto en el norte como en el sur peninsular, de modo que la acción puede realizarse en el mar territorial español y, sin embargo, constatarse el resultado en territorio portugués, o viceversa.

El art. $325 \mathrm{CPe}$, utiliza la expresión «con incidencia incluso en los espacios transfronterizos», cosa que no aparece en el CPp, orientando al intérprete, en esta materia, hacia la idea de que para estos delitos la determinación del lugar de la comisión del delito debe atender al de realización de la acción, conocedor el legislador de que es precisamente en este punto donde radican las dificultades de aplicación práctica de estos delitos. En este sentido, SILVA SÁNCHEZ señala que «en lo relativo a la jurisdicción (...) esta medida parece innecesaria. Pues, en efecto, en lo relativo a la determinación del 'ocus delicti commisi' es dominante la teoría de la ubicuidad. (...) Ahora bien, por otro lado, la mención tiene trascendencia en cuanto a la cuestión sustantiva. El alcance de la referencia legal sería, entonces, indicar que es posible que un Juez o Tribunal español sancione por un delito consumado contra el medio ambiente prescindiendo, de una parte, de la circunstancia de que el peligro para los ecosistemas se ha producido fuera de España, así como, sobre todo, aunque el hecho no sea delictivo en el Estado en cuyo territorio ha tenido lugar la producción del riesgo para el medio ambiente» ${ }^{46}$. Por su parte, QUINTERO OLIVARES se inclina por «reconocer la competencia jurisdiccional simultánea de todos los Estados que hayan sufrido las consecuencias de la acción delictiva. (...) más coherente con el pretendido carácter 'supranacional' del bien jurídico ambiente. (...) la posibilidad de una competencia transnacional y simultánea no tendría por qué ser fuente de conflictos internacionales, sino que podría contribuir a la mejor defensa del bien tutelado. (...) La

\footnotetext{
45 Una relación exhaustiva de los Tratados que afectan directa o indirectamente al régimen de los ríos con cuencas compartidas e incluso algunas veces marca de frontera entre España y Portugal se puede ver en G. QUINTERO OLIVARES, "EI derecho penal ambiental y la contaminación del agua: ríos nacionales y transnacionales", en VV.AA. (E. J. Pérez Alonso, coord.), Derecho, globalización, riesgo y medio ambiente, Tirant lo Blanch, Valencia, 2012, pp. 689-706, p. 702 s.; el mismo, Derecho penal ambiental, Tirant lo Blanch, Valencia, 2013, p. 156. Sobre la tensión entre soberanía y recursos hídricos compartidos véase L. MOVILLA PATEIRO, El Derecho internacional del agua. Los acuíferos transfronterizos, Bosch, Barcelona, 2014, pp. 557 ss.; M. CAMPINS ERITJA, "Los retos de la cooperación regional en Asia central: más sombras que luces en la gestión de los recursos hídricos compartidos", Revista electrónica de estudios internacionales, 19, 2010, pp. 1-27, passim.

46 J.M. SILVA SÁNCHEZ, Delitos contra el medio ambiente, Tirant lo Blanch, Valencia, 1999, p. 47; J.M. SILVA SÁNCHEZ/R. MONTANER FERNÁNDEZ, Los delitos contra el medio ambiente: reforma legal y aplicación judicial, Atelier, Barcelona, 2012, pp. 65 ss.
} 
reserva de la competencia nacional puede dar lugar a situaciones críticas, que desde el punto de vista formal (técnico-jurídico) se resolverían fácilmente diciendo que la teoría de la acción tiene la misma validez que la teoría del resultado, o incluso que la de la 'ubicuidad'. Pero eso no resolvería la lejanía de las víctimas y de las pruebas, con todo el rosario de consecuencias humanas y procesales que eso implica. Por lo tanto, la cesión de competencia en esos casos (que no tiene por qué alcanzar la de la ejecución de la pena, y que es compatible con la fijación de máximos de penas imponibles) creo que sería una buena muestra de efectiva política criminal conjunta, y que, al menos en el territorio UE, debiera ser obligada» ${ }^{47}$.

Una cuestión aparentemente problemática se plantearía en el caso de que la acción tuviese lugar fuera de territorio español, en otro Estado, produciendo el resultado en España. Desde luego, la previsión legal contenida en el art. $325 \mathrm{CPe}$ puede llevar a pensar que cuando esto suceda no habiéndose realizado la acción en España, no resultará de aplicación el $\mathrm{CPe}$, debiendo estar a lo que la legislación penal del Estado de origen del hecho disponga, y en concreto a si contempla una cláusula similar a la establecida en España. De modo que, de no ser así, o siendo atípica en el Estado de origen del hecho, esa conducta quedaría impune. Sin embargo, precisamente por aplicación de la teoría de la ubicuidad, mayoritaria en España ${ }^{48}$, que considera cometido el delito tanto en el territorio donde se realiza la acción como en el territorio donde se produce el resultado, también en este último caso sería de aplicación el CPe. De modo que en el supuesto de que la acción sea cometida en territorio portugués produciéndose el resultado en territorio español, lo cual, en materia de contaminación de aguas, vertidos, captación y extracción, es más que probable, sería de aplicación, en mi opinión, el $\mathrm{CPe}^{49}$. Pero, aunque no fuese así, y a pesar de que el CPp no contiene una cláusula como la contemplada en el art. $325 \mathrm{CPe}$, la conducta no quedaría impune pues el art. 5.0 1. c) CPp dispone que la ley penal portuguesa será de aplicación a determinados delitos cometidos fuera del territorio portugués, siendo uno de aquellos el del art. $279^{\circ} \mathrm{CPp}^{50}$. En consecuencia, habiéndose realizado alguna de las acciones de dicho tipo penal en

\footnotetext{
47 G. QUINTERO OLIVARES, Derecho penal ambiental, Tirant lo Blanch, Valencia, 2013, pp. 85 ss., 157. Sobre la solución a esta cuestión véase infra.

${ }^{48}$ Véase D-M. LUZÓN PEÑA, Lecciones de Derecho Penal, Parte General, 3.a, Tirant lo Blanch, Valencia, 2016, p. 100.

${ }^{49}$ Cfr. J.M. SILVA SÁNCHEZ, Delitos contra el medio ambiente, Tirant lo Blanch, Valencia, 1999 , pp. $47 \mathrm{~s}$.

50 Art. $5.01 \mathrm{c})$ : «1 - Salvo tratado o convención internacional en contrario, la ley penal portuguesa es todavía aplicable a hechos cometidos fuera del territorio nacional: (...) c) Cuando constituya los delitos previstos en los artículos $144 .^{\circ}-\mathrm{A}, 154 .^{\circ}-\mathrm{B}$ e $154 .^{\circ}-\mathrm{C}, 159 .^{\circ}$ a $161.0^{\circ}, 171.0^{\circ}, 172 .^{\circ}, 175 .^{\circ}, 176 . .^{\circ}$ e $278 .^{\circ}$ a $280 .^{\circ}$, desde que el sujeto sea detenido en Portugal y no pueda ser extraditado o entregado en ejecución de orden de detención europea o de otro instrumento de cooperación internacional que vincule al Estado Portugués».
} 
territorio portugués y causando su resultado en territorio español, parece que la norma penal que podría resultar de aplicación sería la portuguesa ${ }^{51}$. En sexto y último lugar, podemos comprobar que la visión del legislador portugués en materia medioambiental es antropocéntrica (moderada) en tanto en cuanto hace depender la respuesta penal de que la conducta lesione o ponga en peligro la vida o salud de las personas ${ }^{52}$, mientras que el legislador español se mueve hacia una visión ecocéntrica, en la que el medio ambiente en sí mismo considerado e, incluso, los recursos naturales como el agua, merecen una protección penal autónoma, independientemente de que su lesión o puesta en peligro pueda tener una incidencia directa en la vida y salud de las personas ${ }^{53}$.

\section{CONCLUSIONES}

1. La protección penal del medio ambiente $y$, en concreto, de un recurso natural como el agua es hoy una realidad contenida en el Derecho positivo de todos los países miembros de la UE. La protección penal del agua se enfrenta a retos derivados del encuentro entre el principio de territorialidad que rige en Derecho penal y la casuística propia de la contaminación de las aguas, en la que está presente una importante variable transfronteriza. La UE viene tratando de armonizar la legislación en materia medioambiental y, por tanto, también en relación con el agua, como lo demuestran sucesivas Directivas que han sido objeto de trasposición. Hoy, sin embargo, son constatables importantes diferencias en la legislación penal en materia de protección del agua, como queda puesto de manifiesto en un estudio de Derecho comparado entre el $\mathrm{CPe}$ y el CPp.

2. Una importante diferencia que se observa entre ambos Código Penales es la relativa a la técnica legislativa empleada. Mientras que en el CPp se diferencia con claridad en materia medioambiental entre delitos de peligro y de lesión, asignando consecuencias jurídicopenales distintas, en el CPe se da una confusión al respecto, indiferenciando las penas en una y otra clase de delitos. Sería deseable un mayor acercamiento, en este punto, a la legislación penal portuguesa.

3. El legislador portugués hace un esfuerzo de mayor taxatividad al definir qué se debe entender por «daño sustancial», requisito exigido por el tipo

\footnotetext{
51 J. DE FIGUEIREDo DIAS, Direito Penal, Parte Geral, Tomo I, 2.a, Coimbra Editora, Coimbra, 2007, pp. 207 ss.; J. DE FARIA COSTA, Noções Fundamentais de Direito Penal (Fragmenta iuris poenalis), Introdução, Coimbra Editora, Coimbra, 2007, pp. 90 ss.

52 L. KREMPEL VARELA, "As tutelas constitucional e penal do meio ambiente", Revista de Estudios Politécnicos, 13, 2010, pp. 75-102, pp. 91 ss.; M.C. MARTINS DE SOUZA/A. ABREU NEVES, "A política nacional do meio ambiente de Portugal", Tópos, 2, 2011, pp. 67-88, pp. 67 ss.

${ }^{53}$ Un análisis pormenorizado del debate entre posiciones antropocéntricas y ecocéntricas se puede ver en S.M. DA GRAÇA COITINHO DAS NEVES, A tutela penal do meio ambiente: uma abordagem de sua legitimidade à luz da teoria funcionalista de Claus Roxin, Universidade do Minho, Braga, 2017, pp. 79 ss. Véase también N.J. DE LA MATA BARRANCO, "El ambiente, como objeto de tutela penal específico y sistemáticamente autónomo, desde una concepción moderadamente antropocéntrica", AA.VV. (S. Mir Puig, J. L. Modolell González, J. I. Gallego Soler, C. S. Bello Rengifo, coords.), Estudios de Derecho penal económico, Livrosca, Caracas, 2002, pp. 569-598, pp. 569 ss.
} 
de contaminación del art. 279. ${ }^{\circ}$ CPp. El art. 325 CPe también utiliza dicha expresión en relación con el resultado exigido, sin embargo, no acota su significado. Nuevamente, sería deseable en aras a una mayor seguridad jurídica que se delimitase por parte del legislador español el significado de tal expresión.

4. En el CPp portugués se incluye un tipo específico (art. 279.07 y 8 ) para los casos de contaminación producida por barcos como consecuencia de descargas de sustancias contaminantes que terminan por afectar a la calidad del agua. El tipo es del tenor siguiente: «cuando hayan sido efectuadas descargas de substancias contaminantes por barcos, de forma aislada o reiterada, de las que resulte un deterioro de la calidad del agua, el sujeto será castigado con la pena de prisión de hasta cinco años». En caso de que la conducta sea imprudente, la pena será de hasta dos años de prisión o pena de multa hasta 360 días. Este tipo penal no se recoge así en el $\mathrm{CPe}$. Aunque es cierto que estas conductas podrían quedar abarcadas por el art. $325 \mathrm{CP}$, lo cierto es que el resultado requerido en el tipo penal portugués es menos exigente que el contemplado en el tipo penal español. Para el tipo penal portugués, basta con que el vertido contaminante afecte a la calidad de las aguas, mientras que el tipo penal español requiere que se produzca un daño substancial en la calidad de las aguas. En mi opinión, sería deseable introducir en el CP español un tipo como el referido en el CPp. Una propuesta de lege ferenda deseable teniendo en cuenta la realidad geográfica española, el tráfico marítimo existente ante las costas, y la habitualidad con la que se dan este tipo de conductas. Circunstancias todas ellas que tienen especial incidencia en Galicia.

5. Las diferencias existentes en las consecuencias jurídicopenales ante las mismas conductas entre ambos Código Penales es realmente llamativa. Sería deseable que hubiese una mayor homogeneidad en las consecuencias jurídicopenales entre ambos Códigos en relación con los tipos penales referidos.

6. Respecto al recurso «agua», el CPe multiplica los tipos penales en los que se cita expresamente, poniendo de manifiesto de este modo la importancia que se le otorga en el Orden penal. Las referencias a este recurso entre los delitos medioambientales en el CPp son mucho más escasas y débiles. En mi opinión, considero más deseable la opción del legislador español que cita expresamente en numerosos tipo penales el agua como objeto material del delito.

7. Uno de los principales problemas a los que se podría enfrentar la lucha contra la criminalidad medioambiental, en particular, aquélla con incidencia en las cuencas hidrográficas (también en el mar) es el relativo al de la territorialidad y la determinación de la ley penal aplicable. Sin embargo, la aplicación dominante de la teoría de la ubicuidad en España, así como la previsión del art. 5.0 1. c) CPp, nos lleva a pensar que es difícil que por esta vía alguna de las conductas contaminantes del agua que puedan presentar relevancia penal puedan quedar impunes.

8. A modo de conclusión final, se puede señalar, por todo lo dicho, que se hace imprescindible seguir trabajando en el proceso de integración y 
armonización legislativa en materia penal, cuya importancia es todavía mayor cuando de delitos contra el medio ambiente en general $y$, en particular, de protección penal del agua se trata.

\section{BIBLIOGRAFÍA}

A. ABREU NEVES, "A política nacional do meio ambiente de Portugal", Tópos, 2, 2011, pp. 67-88.

M.C. ALASTUEY DOBON, El delito de contaminación ambiental (Artículo 325.1 del Código penal), Comares, Granada, 2004.

R. BARBA ÁLVAREZ, "El agua como derecho fundamental y su protección jurídico-penal", Revista Prolegómenos - Derechos y Valores, 27, pp. $213-229$.

J. BAUCELLS I LLADÓS, Nuevas perspectivas de la política criminal europea en materia medioambiental, Atelier, Barcelona, 2007.

J.M. BERMÚDEZ REQUENA, "Contaminación de acuíferos y prueba pericial de recogida y análisis de muestras de agua: aspectos procesales penales", en VV.AA. (Á. Sánchez Bravo, ed.), Agua: un recurso escaso, Arcibel, Sevilla, 2006, pp. 45-65.

C. BLANCO LOZANO, La tutela del agua a través del Derecho penal, Bosch, Barcelona, 2000.

C. CANCELA OUTEDA, "La Eurorregión Galicia-Norte de Portugal: un escenario de cooperación internacional", Razón y Palabra, 74, 2011.

C.J. CANTERO CERQUELLA, La responsabilidad penal de los funcionarios por delitos ambientales, Reus, Madrid, 2010.

P.J. CUESTA PASTOR, "Delitos relativos al mercado y a los consumidores y delitos contra el orden público", en (J.M. Peris Riera, dir.)/P. Cuesta Pastor, coord.), La tutela penal del agua, Dykinson, Madrid, 2011, pp. 273-283.

S.M. DA GRAÇA COITINHO DAS NEVES, $A$ tutela penal do meio ambiente: uma abordagem de sua legitimidade à luz da teoria funcionalista de Claus Roxin, Universidade do Minho, Braga, 2017.

J. DE FARIA COSTA, Noções Fundamentais de Direito Penal (Fragmenta iuris poenalis), Introdução, Coimbra Editora, Coimbra, 2007.

J. DE FIGUEIREDO DIAS, Comentário Conimbricense do Código Penal, Tomo II, Coimbra Editora, Coimbra, 1999.

J. DE FIGUEIREDO DIAS, Direito Penal, Parte Geral, Tomo I, 2.a, Coimbra Editora, Coimbra, 2007.

P.M. DE LA CUESTA AGUADO, Causalidad de los delitos contra el medio ambiente, 2. a, Tirant lo Blanch, Valencia, 1999.

P.M. DE LA CUESTA AGUADO, "Energía nuclear: arts. 343 y 345", en VV.AA. (F.J. Álvarez García/J.L. González Cussac, dirs.), Consideraciones a propósito del Proyecto de Ley de 2009 de modificación del Código Penal, Tirant lo Blanch, Valencia, 2010, pp. 353-357.

N.J. DE LA MATA BARRANCO, "El ambiente, como objeto de tutela penal específico y sistemáticamente autónomo, desde una concepción moderadamente antropocéntrica", VV.AA. (S. Mir Puig, J. L. Modolell 
González, J. I. Gallego Soler, C. S. Bello Rengifo, coords.), Estudios de Derecho penal económico, Livrosca, Caracas, 2002, pp. 569-598.

N.J. DE LA MATA BARRANCO, "Derecho comunitario y Derecho estatal en la tutela penal del ambiente", Revista Electrónica de Ciencia Penal y Criminología, 2, 2000.

N.J. DE LA MATA BARRANCO, "Delitos contra el urbanismo y la ordenación del territorio y delitos contra el ambiente", en VV.AA., Derecho penal económico y de la empresa, Dykinson, Madrid, 2018, pp. 629-684.

J.A. DE VEGA RUIZ, Delitos contra el medio ambiente, ordenación del territorio, patrimonio histórico, flora y fauna en el Código Penal de 1995, Colex, Madrid, 1996.

L. ESCAJEDO SAN EPIFANIO, El medio ambiente en la crisis del Estado social. Su protección penal simbólica, Comares, Granada, 2006.

J. FEIJOO SÁNCHEZ, Sanciones para empresas por delitos contra el medio ambiente. Presupuestos dogmáticos y criterios de imputación para la intervención del Derecho Penal contra las empresas, Civitas, Madrid, 2002.

A. FORTES MARTÍN, Vertidos y calidad ambiental de las aguas. Regulación jurídico-administrativa, Atelier, Barcelona, 2005.

W. FRISCH, "Derecho penal y protección del clima", Indret, 4, 2015, pp. 1-22.

J.L FUENTES OSORIO, "Accesoriedad administrativa y delito ecológico", en VV.AA. (E. Pérez Alonso/E. Arana García/P. Mercado Pacheco/J.L. Serrano Moreno, eds.), Derecho, globalización, riesgo y medio ambiente, Tirant lo Blanch, Valencia, 2012, pp. 707-733.

A. JORGE BARREIRO, "El bien jurídico protegido en los delitos contra el medio ambiente en el CP de 1995", en VV.AA. (A. Jorge Barreiro, dir./M. Cancio Meliá, coord.), Estudios sobre la protección penal del medio ambiente en el ordenamiento jurídico español, Comares, Granada, 2005, pp. 1-73.

L. KREMPEL VARELA, "As tutelas constitucional e penal do meio ambiente", Revista de Estudios Politécnicos, 13, 2010, pp. 75-102.

J.A. LASCURAÍN SÁNCHEZ, "Elogio del artículo 325 del Código penal", en VV.AA. (A. Jorge Barreiro, dir./M. Cancio Meliá, coord.), Estudios sobre la protección penal del medio ambiente en el ordenamiento jurídico español, Comares, Granada, 2005, pp. 265-295.

E.B. MARÍN DE ESPINOSA CEBALLOS, "El principio non bis in ídem: la acumulación de sanciones penales y administrativas en la protección del medio ambiente", en VV.AA. (E. Pérez Alonso/E. Arana García/P. Mercado Pacheco/J.L. Serrano Moreno, eds.), Derecho, globalización, riesgo y medio ambiente, Tirant lo Blanch, Valencia, 2012, pp. 735-757.

M. MARQUĖS I BANQUÉ, "Artículo 325", en VV.AA. (G. Quintero Olivares, dir./F. Morales Prats, coord.), Comentarios al Código Español, Tomo II, 7.a ed., Aranzadi, Cizur Menor (Navarra), 2016, pp. 807-820.

B. MARTÍN GARCÍA, La Protección penal del medio ambiente y su relación con la seguridad pública y los derechos fundamentales, Dykinson, Madrid, 2017. 
D-M. LUZÓN PEÑA, Lecciones de Derecho Penal, Parte General, 3.a, Tirant lo Blanch, Valencia, 2016.

N. MATELLANES RODRÍGUEZ, Medio ambiente y funcionarios públicos. Análisis del tipo objetivo del artículo 329 del Código Penal, Bosch, Barcelona, 2000.

A. MATEOS RODRÍGUEZ-ARIAS, Derecho penal y protección del medio ambiente, Colex, Madrid, 1992.

R. MONTANER FERNÁNDEZ, "La posible responsabilidad penal del auditor ambiental", Indret, 2, 2012, pp. 1-27.

L. MORILLAS CUEVA, "Las diversas variables de la protección penal del agua en el ámbito punitivo", en VV.AA. (J.M. Peris Riera, dir./P.J. Cuesta Pastor, coord.), La tutela penal del agua, Dykinson, Madrid, 2011, pp. 37-83.

D.L. MORILLAS FERNÁNDEZ, "El delito de estragos: especial referencia a los causados por perturbación o interrupción del suministro de agua", en VV.AA. (J.M. Peris Riera, dir./P. Cuesta Pastor, coord.), La tutela penal del agua, Dykinson, Madrid, 2011, pp. 317-343.

L. MOVILLA PATEIRO, El Derecho internacional del agua. Los acuíferos transfronterizos, Bosch, Barcelona, 2014.

J.M. PERIS RIERA, "La protección penal del agua en España, Alemania e Italia", Diario La Ley, 7366, 2010, pp. 1-8.

J.M. PERIS RIERA, "Tutela penal del agua", en VV.AA. (J.M. Peris Riera dir./P. Cuesta Pastor, coord.), La tutela penal del agua, Dykinson, Madrid, 2011, pp. 21-36.

J.M. PRATS CANUT/M. MARQUÈS I BANQUÉ/C. MORÁN MORA, Derecho penal ambiental y Derecho comunitario. La Directiva IP, Aranzadi, Cizur Menor (Navarra), 2002.

L.M. PUENTE ABA, "Los delitos contra los recursos naturales y el medio ambiente (arts. 325 y 326)", en VV.AA. (P. Faraldo Cabana, dir./L.M. Puente Aba, coord.), Ordenación del territorio, patrimonio histórico y medio ambiente, Tirant lo Blanch, Valencia, 2011, pp. 235-279.

G. QUINTERO OLIVARES, "El derecho penal ambiental y la contaminación del agua: ríos nacionales y transnacionales", en VV.AA. (E. J. Pérez Alonso, coord.), Derecho, globalización, riesgo y medio ambiente, Tirant lo Blanch, Valencia, 2012, pp. 689-706.

G. QUINTERO OLIVARES, Derecho penal ambiental, Tirant lo Blanch, Valencia, 2013.

J.M. RAMA SERRANO, "La protección del dominio público hidráulico", en VV.AA. (A. SÁNCHEZ BRAVO, ed.), Agua: un recurso escaso, Arcibel, Sevilla, 2006, pp. 23-35.

M.P. RIBEIRO FARIA, "Direito penal do ambiente - sua reforma e perspectivas de evolução", Revista do CEJ, 2, 2008.

A.M. RODRIGUES, "A propósito do crime de poluição (artigo 279.0 do Código Penal)", Direito e Justiça. Revista da Faculdade de Direito da Universidade Católica Portuguesa, 12, 1998. 
S. RODRÍGUEZ FERRÁNDEZ, "El agua: bien jurídico-penal protegido", en VV.AA. (J.M. Peris Riera, dir./P. Cuesta Pastor, coord.), La tutela penal del agua, Dykinson, Madrid, 2011, pp. 85-120.

P. RODRÍGUEZ LÓPEZ, Medio ambiente, territorio, urbanismo y Derecho penal, Bosch, Barcelona, 2007.

P.A. RUBIO LARA, "Delitos de distracción del curso de las aguas públicas o privadas sin autorización y de defraudación del agua (artículos 247 y 255 del Código penal)", en VV.AA. (J.M. Peris Riera, dir./P. Cuesta Pastor, coord.), La tutela penal del agua, Dykinson, Madrid, 2006, pp. 191-211.

M.D. SERRANO TÁRRAGA/A. SERRANO MAÍLLO/C. VÁZQUEZ GONZÁLEZ, Tutela penal ambiental, 3. ${ }^{a}$ ed., Dykinson, Madrid, 2017

J.M. SILVA SÁNCHEZ, Delitos contra el medio ambiente, Tirant lo Blanch, Valencia, 1999.

J.M. SILVA SÁNCHEZ/R. MONTANER FERNÁNDEZ, Los delitos contra el medio ambiente: reforma legal y aplicación judicial, Atelier, Barcelona, 2012.

F.J. SOSPEDRA NAVAS, "De los delitos contra los recursos naturales y el medio ambiente. Capítulo III", en VV.AA. (J.A. Domínguez Luis/E. Farré Díaz/F.J. Sospedra Navas/J. Hernández García/J. Grinda González/M.J. Herreros Ventosa/J.V. Hervas Vercher, eds.) Delitos relativos a la ordenación del territorio y protección del patrimonio histórico, medio ambiente y contra la seguridad colectiva (delitos de riesgo catastrófico e incendios), Bosch, Barcelona, 1999, pp. 167221.

J. SOUTO DE MOURA, "Crimes Ambientais. Jornada sobre a revisão do Código Penal", Revista do CEJ, 8, 2008.

C. SUÁREZ-MIRA RODRÍGUEZ, "EI bien jurídico protegido", en VV.AA. (P. Faraldo Cabana, dir./L.M. Puente Aba, coord.), Ordenación del territorio, patrimonio histórico y medio ambiente en el Código Penal y la legislación especial, Tirant lo Blanch, Valencia, 2011, pp. 77-91.

J. TERRADILLOS BASOCO, "Delitos relativos a la protección del patrimonio histórico y del medio ambiente", en VV.AA. (J. Terradillos Basoco, ed.), Derecho penal del medio ambiente, Trotta, Madrid, 1997, pp. 35-59, p. 48.

F. TORRÃO, C. ARAGÃO SEIA, Recensión del libro "Vale a pena o Direito penal do ambiente?" de Paulo de Sousa Mendes, Lusíada. Dereito, 13, 2015, pp. 169-171.

C. TRABADO ÁlVAREZ, Protección penal del Medio ambiente. Derecho penal y normativa extrapenal sobre Medio ambiente, Septem, Oviedo, 2001.

F. VICENTE DÁVILA, Evaluación de impacto ambiental transfronteriza entre España y Portugal, Atelier, Barcelona, 2016.

J. URRAZA ABAD, Delitos contra los recursos naturales y el medio ambiente, La Ley, Madrid, 2001.

J.L. ZAMORA MANZANO, "El ilícito penal medio ambiental en Roma: la contaminación y degradación de las aguas en el espacio urbano y rural", en VV.AA. (M. Calzada González/F. Camacho de los Ríos, 
coords.), El Derecho penal: de Roma al Derecho actual. VII Congreso Internacional y $X$ Iberoamericano de Derecho romano, Edisofer, Madrid, 2005, pp. 675-700. 